\title{
When Physics, Economics and Reality Collide: The Challenge of Cheap Orbital Access
}

\author{
Dr. John Jurist* \\ CRM, Inc., Billings, Montana, 59105 \\ Dr. Sam Dinkin ${ }^{\dagger}$ \\ Optimal Auctions, Inc., Austin, Texas, 78746 \\ and \\ Dr. David Livingston ${ }^{*}$ \\ The Space Show, Tiburon, CA, 94920
}

\begin{abstract}
Engineering problems are only part of the difficulty of achieving a price per pound of less than \$1,000 to low earth orbit (LEO). Insurance and range costs can each cost more than $\$ 1,000$ per pound if no effort is put into reducing them. Achieving low cost to LEO also requires solving problems associated with the economic limitations of chemical rockets, lack of business planning, and failure to identify a workable path that will take us from an immature to a mature launch industry. A mature launch industry would exhibit low cost to LEO and significant flight rates by reusable vehicles with long lifetimes. When today's factors, limitations, and reality denials are combined, we believe that they prolong the difficulties of achieving low cost, routine flights to LEO. In other words, we end up inadvertently supporting the status quo.
\end{abstract}

\section{Nomenclature}

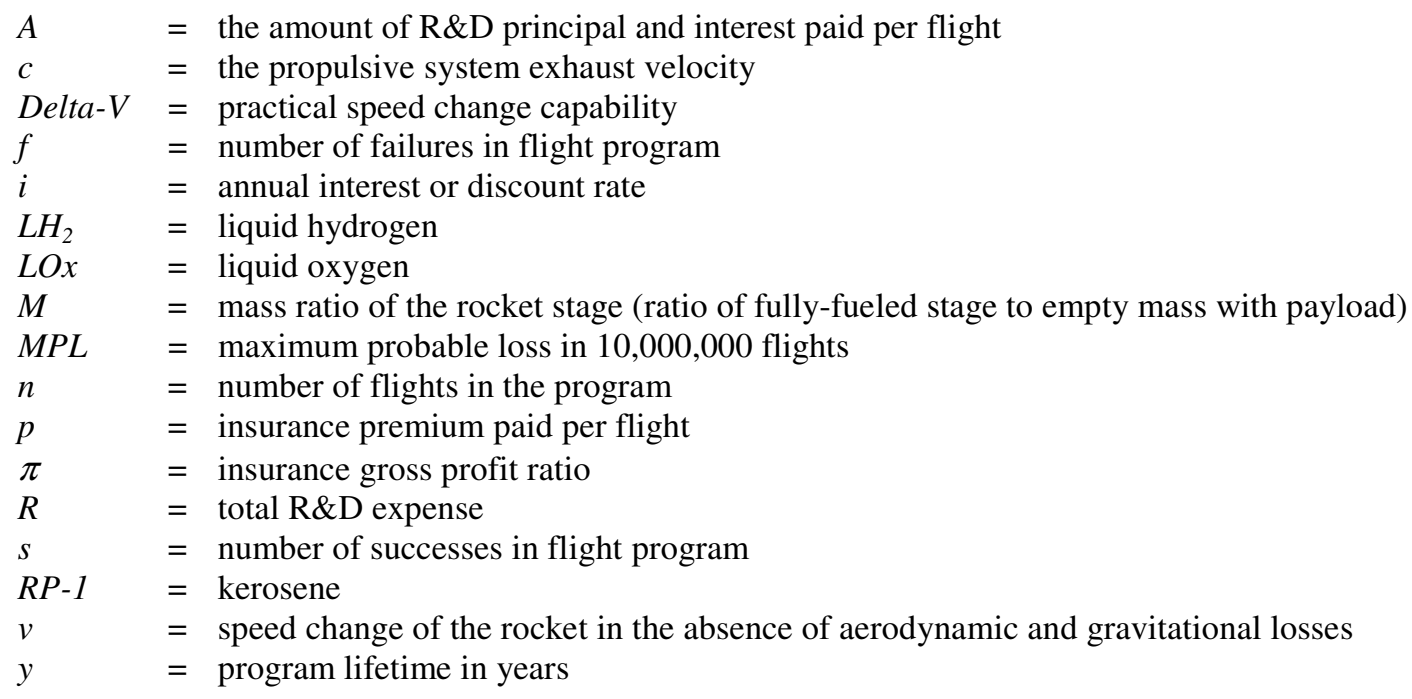

\section{Introduction}

DRESENT costs for putting freight into orbit are high for the same reasons that jet travel on Earth would be expensive if the corresponding rules were followed for the operation:

\footnotetext{
* President; 1540 Lake Elmo Drive, Ste. 5, Billings, MT 59105; non-member.

${ }^{\dagger}$ Chief Economist; 3101 Lating Stream Lane, Austin, TX 78746; member.

¥ Founder and Host; P.O. Box 95, Tiburon, CA 94920; member.
} 
1) There shall be no more than one flight per month.

2) The airplane shall be thrown away after each flight.

3) The entire cost of the international airports at both ends of the flights shall be covered by the freight charges.

These comments are as valid today as they were when Theodore Taylor made them in $1966 .{ }^{1}$ We would add two more rules to Taylor's:

4) Jet engines will have narrow safety margins and will not run more than a few hours without a major overhaul.

5) Aviation management will consistently avoid high quality business planning and will ignore the technical and financial realities related to their industry.

One of the central tenets of the alternative space access or "alt.space" community is that modern advances in technology and materials will allow cheap access to LEO. An assumed consequence is that Homo sapiens will eventually evolve into a space-faring race. Unfortunately, current technological, economic, and regulatory realities combine to forbid payload delivery to LEO for less than $\$ 1,000$ per pound without changing the rules of the game. Simply creating fleets of reusable launch vehicles (RLVs) is unlikely to solve the problem unless they are large and have lifetimes of many frequent flights. Present technology might permit large, reusable vehicles, but there are many critical missing factors. Nobody has demonstrated the ability to design, fabricate, and fly such vehicles. Nobody has documented a convincing mechanism for financing and then amortizing the necessary research and development to create such vehicles. Nobody has documented a clear, solid business plan to implement the program required to do so. Nobody has demonstrated the market that would support the costs of creating such vehicles. Finally, nobody has proposed a viable strategy to go from our present flight rate of expendables to the high flight rates of RLVs projected for the mature industry which would permit achieving low cost flights to LEO. The nontechnical factors of insurance and range costs are two of many major obstacles to attaining this goal.

There is a scenario leading a potentially successful outcome. This is the methodical evolution from a commercially successful suborbital private-sector industry to private-sector orbital space flight. If a successful suborbital industry develops, it will result from solid and well grounded business planning, streamlined business and management operations, proper use of financial and accounting processes, skilled labor and management, and use of well designed checklists and safety considerations. Evolving succcessful suborbital companies to orbital operations will require emulating the successful aspects of suborbital development. It will mean no more fantasy business planning and financial proposals. Thus, orbital space access can occur through a step by step process which builds on the foundation of what has been shown to work regarding suborbital commercial space flight. Once the door opens for commercial orbital flight, solid business planning and operational systems improvements will enable lower cost orbital space access. This will produce track records that make sense to the financial world. Eventually, a mature industry with all its benefits can be obtained by steady growth and development.

\section{A. Basic Concepts}

At the Earth's surface, circular orbital velocity is about 7,905 meters per second. ${ }^{2}$ This figure declines with orbital altitude and attaining it is eased somewhat by launching to the east. A low latitude easterly launch can gain perhaps 350 to 400 meters per second. However, losses from atmospheric drag and gravity during vehicle acceleration and climb to orbital altitude generally exceed the gain. The net result is that an effective penalty of about 15 to 25 percent is added to the basic orbital velocity requirement for a real-world launch to LEO. ${ }^{3}$ As shown in Table 1 , a Delta- $V$ of about 9 to 10 kilometers per second is required for a launch vehicle to deliver a payload to LEO. This involves expenditure of a lot of energy. Since single-stage-toorbit (SSTO) capability has yet to be fully demonstrated, our society is effectively dependent on some variant of two stage launch vehicles to attain LEO.

A single-stage formulation of the classic rocket equation dictates that: ${ }^{4}$

\section{Table 1. Required Delta- $V$ to Attain LEO.}

$\begin{array}{cl}\text { Loss Penalty }(\%) & \text { Delta- } V(\mathrm{~m} / \mathrm{s}) \\ & \\ 0 & 7,905 \\ 5 & 8,300 \\ 10 & 8,696 \\ 15 & 9,091 \\ 20 & 9,486 \\ 25 & 9,881\end{array}$

The exhaust velocity is largely determined by the choice of propulsive system-especially the propellant characteristics. Assuming that both stages of a two stage vehicle have the same mass ratio and exhaust velocity, the required
Table 2. Propellant Fraction of Two Stage System to LEO.

\begin{tabular}{clll} 
& & \multicolumn{2}{c}{ Velocity Loss Margin } \\
Propellant Combination & $c, \mathrm{~m} / \mathrm{s}$ & $15 \%$ & $25 \%$ \\
$R P-1$ and $L O x$ & 2,793 & 0.804 & 0.830 \\
$L_{2}$ and $L O x$ & 3,898 & 0.688 & 0.719
\end{tabular}

2

American Institute of Aeronautics and Astronautics 
proportion of a launch system comprised of propellants is roughly 70-80 percent depending on propellant combination as shown in Table $2 .^{5}$

If one allows a 15 percent margin for aerodynamic and gravitational losses, a liquid oxygen and hydrocarbon (LOx/RP-1) two stage launch system must consist of 80.4 percent propellant by weight to attain LEO under the assumption of equal performance and mass ratios for each stage. This means that only 19.6 percent of the launch system is available for motors, propellant tanks, propellant pumps, support structures, guidance and control systems, interstage assemblies, staging mechanisms, recovery systems (if any), and payload. There are some tricks that can ameliorate this situation slightly, such as jettisoning the payload and interstage shrouds before completion of the propellant burn, assigning more of the Delta- $V$ budget to the second stage, and launching to the east for low inclination orbits, but these tricks only affect performance around the margin.

Rocket motor specific impulse varies with ambient pressure and exhaust nozzle expansion ratio. Ideally, the exhaust plume pressure at the nozzle exit is equal to the ambient pressure. If the exhaust stream is over-expanded to lower than ambient pressure, motor efficiency suffers greatly. For example, the Merlin first stage motor for the Space Exploration Technologies Corporation (SpaceX) Falcon-I vehicle demonstrates a sea level specific impulse of 255 seconds and a vacuum specific impulse of 304 seconds. Thus, vacuum performance of the Merlin is roughly 20 percent better than sea level performance. The Falcon-I second stage motor, which is optimized for near vacuum operation (324,000 feet altitude at ignition), has a specific impulse of 327 seconds. ${ }^{6}$

One way to exploit the improved performance associated with optimizing a motor to near vacuum conditions is the divide the Delta- $V$ budget unevenly between the stages. By lowering the first stage Delta- $V$, second stage ignition occurs earlier, but still at near vacuum conditions. Thus, the second stage effective exhaust velocity is improved and provides marginal improvement in launch system efficiency.

\section{B. Air Launch}

As mentioned previously, a low latitude launch to the east reduces the Delta- $V$ requirement by 350 to 400 meters per second. A ground launch adds an additional Delta- $V$ burden of between 100 and 160 meters per second for air drag, and between 1,100 to 1,500 meters per second for gravitational losses. Launching from a balloon at, for example, 80,000 feet reduces the gravitational Delta-V burden by no more than half compared to a ground launch. Even elimination of most of the air drag burden by a high altitude balloon launch at, for example, 80,000 feet leaves a total Delta- $V$ requirement of roughly 8,200 meters per second. Compared to a 15 percent velocity margin for a ground launch, this reduces the propellant fraction from 80.4 percent to 77.1 percent for a $L O x / R P-1$ or equivalent system.

Air launch from a balloon has severe limitations on allowed vehicle mass. For example, a recent large balloon launch involved a 40,000,000 cubic foot volume of helium to carry a total liftoff weight (balloon, controls, and payload) of about 9,300 pounds. $^{7}$ A 40,000,000 cubic foot sphere has a diameter of about 420 feet. Launching a balloon of this volume involves many problems related to its size and wind conditions. Yet, a liftoff weight of 9,300 pounds implies a rocket with a fuelled mass that is no more than perhaps 8,000 pounds. The payload to LEO of a two stage rocket with a fully fuelled mass of 8,000 pounds is minimal.

Launching a vehicle like the Orbital Sciences Corporation Pegasus horizontally from an air breathing "mother ship" at perhaps 40,000 feet and 500 miles per hour potentially reduces the required Delta- $V$ by roughly 750 meters per second. The required propellant fraction is potentially reduced by an amount similar to the reduction obtained by a balloon launch at 80,000 feet. Other potential advantages of air launch include low energy abort modes, more flexible launch windows, and the ability to ferry the launch vehicle to a remote location to provide convenient access to the desired orbit and partially abate launch fees. However, if the launch vehicle track intrudes on a national range, range and tracking fees will still apply. ${ }^{8}$ Transporting the launch system to a remote, foreign location may involve export regulations for launchers originating in the United States. Insurance fees may also be reduced by ferrying to an uninhabited area.

Technical limitations also apply for air launch. Henry's thesis reports that the Pegasus is limited to a payload of 976 pounds into LEO with a vehicle dry weight of 5,395 pounds. ${ }^{9}$ The "mother ship" for this vehicle is a modified Lockheed L-1011 wide-bodied jet. Reportedly, development costs for the Pegasus approximated $\$ 150$ million or about $\$ 30,000$ per pound. Using a modified Boeing 747 as a "mother ship" might allow a maximum vehicle launch weight of up to about 180,000 pounds. The largest aircraft in the world, the Antonov An-225, is limited to a maximum payload of 551,150 pounds. ${ }^{10}$ That limits the maximum fully fuelled weight of an air launched rocket to perhaps 545,000 pounds. When the launch vehicle is dropped horizontally from the "mother ship," it accelerates out and then pitches up into a climb to get above effective atmosphere. This maneuver adds to the Delta- $V$ budget because of turning or steering losses and the increased drag associated with the non-zero angle of attack during the pitch maneuver. In addition, wings add a significant mass penalty for a system used only during the initial pitch 
maneuver and potentially during landing for an RLV. The Pegasus has an overall propellant fraction of 90 percent compared to 91 percent for an Atlas-II. Another approach is to drop the launch vehicle from an aircraft flying horizontally and then rotate it until it is vertical before igniting the rocket motors. The required robustness of the vehicle is increased because it must withstand the rotation and maintain some cross wind capability until its translational speed is mostly lost before ignition. If there is a motor failure, the fuelled launch vehicle may well be lost. A safety advantage results from the launch vehicle climbing out behind the "mother ship" rather than dropping behind and below and then accelerating and climbing ahead of the "mother ship." The latter entails some potential collision hazard between the launch vehicle and the "mother ship."

A winged vehicle launching horizontally from ground level experiences a 200 to 300 meters per second penalty relative to a vertical takeoff vehicle. ${ }^{11}$ In addition, it must carry a landing gear designed to accommodate launch weight. This latter factor is one basis for some of the proposals for taking on fuel and oxidizer after takeoff for some horizontal takeoff concepts.

The stresses on a vertical launch vehicle are primarily longitudinal or axial. The stresses on a horizontal take off vehicle are initially transverse and bending and then transition to axial during climb out. Designing a structure to accommodate these stresses imposes an additional weight penalty for horizontal takeoff vehicles compared to vertical takeoff concepts.

Because of the limitations of the various horizontal takeoff and air launched concepts, we confined our analysis to vertical takeoff two stage vehicles launched from ground level.

\section{Hydrogen Propellant}

Using $\mathrm{LH}_{2}$ as a fuel reduces the propellant fraction, but the density of liquid hydrogen is only 12.3 percent that of $R P-1 .^{5}$ The required tank volume and associated mass is increased markedly as a consequence and offsets the roughly 40 percent performance gain of hydrogen compared to hydrocarbon fuel without introducing undue program risk. Besides, the stuff is comparatively expensive and difficult to handle. With a liquid hydrogen cost of about $\$ 1.40$ per pound, overall propellant costs of a $\mathrm{LOx} / \mathrm{LH}_{2}$ system will run roughly $\$ 0.40$ per pound. As will be shown below, this is more than $33 \%$ higher the cost per pound of $R P-1$ and $L O x^{12}$ Yet, Table 2 shows that the required propellant fraction of a two stage vehicle is only reduced from roughly 80 percent to about 70 percent by replacing $\mathrm{RP}-1$ with $\mathrm{LH}_{2}$. The net savings in vehicle weight to achieve the same payload is offset by the more difficult engineering of a hydrogen system and the increased propellant cost. This makes hydrogen propellant inconsistent with low cost routine operation at this time. As a consequence, the following analysis will be confined to $R P-1$ and $L O x$ as a propellant combination.

\section{Methodology}

We examined programmatic costs of baseline expendable launch vehicles (ELVs) and RLVs capable of delivering 1,000 pounds to LEO. These costs were separated into direct and indirect costs for total flight programs of 500 launches. Then, to examine the effects of some of the more sensitive variables on the model, we tested the effects of payload size on costs by analyzing ELVs and RLVs capable of delivering as much as 100,000 pounds to LEO. We also analyzed the effects of flight lifetime per vehicle and fleet size for the RLVs.

As part of the analysis, we attempted to counteract the effects of our biases by typically understating the actual costs of the various elements by making optimistic assumptions whenever hard figures were not available. This understatment was substantial in the case of research and development (R\&D) and fabrication costs. The costs of $R \& D$ and fabrication are compared to similar costs for aircraft after correction for vehicle mass. The various cost and mass relationships were scaled between extremes by the logarithm of vehicle mass or payload.

As an example of our optimistic assumptions, we can compare our payload to vehicle mass relationships to the SpaceX Falcon series. ${ }^{6}$ The design payload capability to LEO for the Falcon-I and Falcon-V is 1,474 and 13,244 pounds, respectively. Gross launch weights are published as 60,000 and 400,000 pounds, respectively. Using an average exhaust velocity of 2,798 meters per second (specific impulse of 286 seconds versus 255 seconds at sea level and 304 seconds in vacuum for the Merlin motor used in the Falcon-I), a mission Delta-V of 9,091 meters per second, and equal Delta- $V$ for each stage results in vehicle dry weights (including payload) of 11,820 and 78,553 pounds for vehicles with the published Falcon payload capabilities. This yields payload to vehicle dry weight ratios of 12.5 and 16.9 percent. The assumptions we used in our analysis for the 1,000 and 100,000 pound payload ELVs correspond to 14.8 and 27.9 percent, respectively, when interpolated for the Falcon-I and Falcon-V payloads.

\section{A. Expendable Launch Vehicles}

With this basic information, some hypothetical launch systems can be characterized. ELVs will be considered first and compared to RLVs. The baseline ELV will be assumed to carry a payload of 1,000 pounds to LEO and 
have an optimistic payload to dry vehicular mass ratio of 12.5 percent. Then, the total vehicular dry mass, exclusive of payload, is 7,000 pounds and the total propellant load for $R P-1$ and $L O x$ is 32,607 pounds for a total take-off mass of 40,607 pounds. This is considered optimistic in that the 7,000 pounds dry structural mass consists of a two stage vehicle with total tankage holding 32,607 pounds of propellant, motors and pumps for both stages, guidance and control systems, an abort system (typically required for launches on national ranges), payload shroud, etc. with sufficient structural integrity to withstand all launch loads with an acceptable safety factor.

We assume fuel costs are $\$ 0.31$ per pound and $L O x$ costs about $\$ 0.30$ per pound based on local prices in Montana. An oxidizer to fuel mixture ratio of 2.24 by weight is also assumed. This results in a propellant cost of $\$ 9,853$ per flight exclusive of losses. Rounding to $\$ 10,000$ for reserve adds 18 cents per pound of payload to the propellant cost of $\$ 9.82$ per pound of payload. If a sufficient flight rate is assumed, a $L O x$ plant can be fabricated on site for a considerable capital investment to reduce these direct costs.

A direct incremental vehicle fabrication cost of $\$ 75$ per pound exclusive of research, development, and design costs results in a vehicular structural cost about $\$ 525,000$ per unit. For comparison, an upscale automobile costs on the close order of $\$ 20$ per pound. Commercial aircraft costs run in the neighborhood of $\$ 100$ to 300 per pound. The new Airbus A380 costs approximately $\$ 230$ per pound ( $\$ 280$ million retail sales price less 50 percent for fixed costs and an empty weight of 608,000 pounds). ${ }^{13}$ However, commercial aircraft are designed and fabricated for lifetimes of perhaps 30,000 flights. This tends to boost both $R \& D$ and fabrication costs. An offsetting factor is that vehicles such as the A380 are evolutionary end products that can use tooling and facilities amortized on previous model production runs. Airbus also enjoys significant government subsidies that may not be reflected in their stated R\&D and production costs.

Assuming a preflight preparation cost of $\$ 5,000$ (100 man hours at $\$ 50$ per hour) results in a direct launch cost per flight of $\$ 540,000$. This preparation labor estimate approximates twice the maintenance man hours consumed per flight hour of high performance military aircraft. As will be seen below, the preflight preparation cost estimate adds $\$ 5$ per pound of payload to the direct flight costs.

However, this does not represent total flyaway costs. Program research and development must be amortized over the launch program lifetime. With a total program of 500 flights, a $\$ 50$ million R\&D program is amortized at $\$ 100,000$ per flight exclusive of interest. That comes to $\$ 100$ per pound of payload. In addition, launch facilities (launch pads, checkout structures and facilities, telemetry, etc.) must be amortized over the program lifetime. Assuming a very favorable cost of about $\$ 2$ million for these facilities results in a per flight cost of $\$ 4,000$ exclusive of interest.

In addition, range costs are quite significant. Currently, they are estimated at between $\$ 1$ million and $\$ 1.3$ million for flight day on a national range. ${ }^{14}$ These costs are governmentally controlled and usually passed on to the user. If not, the costs are absorbed by the taxpayer in one fashion or another. They could be reduced somewhat by performing more than one flight daily or by using strong political negotiation for discounted costs, but the underlying activities resulting in the costs are unlikely to be reduced in the current risk averse culture. In essence, range costs are a political problem and have the effect of stifling demand. Insurance, including launch, delivery, and liability coverage is another expensive component of Table 3. ELV Launch Costs over 500 Flights (without interest)

$\begin{array}{lc}\text { Vehicle Structure } & \$ 525,000 \\ \text { Propellant } & \$ 10,000 \\ \text { Prelaunch Preparations } & \$ 5,000 \\ \text { Direct Launch Costs } & \$ 540,000 \\ \text { Amortized R\&D } & \$ 100,000 \\ \text { Amortized Launch Facility } & \$ 4,000 \\ \text { Range Costs } & \$ 477,000 \\ \text { Insurance } & \$ 380,000 \\ \text { Indirect Launch Costs } & \$ 961,000 \\ \text { Total Launch Costs } & \$ 1,501,000 \\ \text { Cost per Pound of Payload } & \$ 1,501\end{array}$

launch costs. These costs currently run about 15 percent of vehicle, payload, service, and ground facility costs. ${ }^{15}$ Of course, insurance costs will trend downward as vehicle reliability increases and purchasing methodology improves. The current estimate of insurance cost is based on historical failure rates of ELVs and traditional brokered transactions.

Table 3 summarizes these costs over a program lifetime of 500 flights. The table does not include payload insurance costs. The direct costs are $\$ 540$ per pound to LEO, indirect costs are $\$ 961$ per pound to LEO, and total fly-away costs are $\$ 1,501$ per pound for a total cost of more than $\$ 750$ million to deliver 500,000 pounds to LEO. In this table, range costs are based on negotiated figures provided by SpaceX as a function of payload weight. These costs are lower than the range costs as outlined above and reflect taxpayer subsidies of unknown magnitude. 


\section{B. Reusable Launch Vehicles}

An obvious thought is to drive launch costs down by reusing the launch vehicles. This does nothing to reduce the range costs.

Other costs creep into the system with RLVs. Assume that a program of 500 flights using a fleet of 5 vehicles is created. This assumes a lifetime of 100 flights per vehicle. From an historical standpoint, the only partial RLV capable of payload delivery to LEO, the Shuttle Transportation System (STS), has a higher loss rate than this. From a business standpoint, vehicle lifetimes of more than 100 flights are to be desired because vehicle fabrication costs and program R\&D costs can be amortized over many more flights. If more flights per vehicle proves feasible, it would drive indirect launch costs down and make spacecraft operations more like aircraft operations. Because RLVs must be more robust than ELVs in order to withstand recovery and multiple uses, the payload fraction is lower than in ELVs. The longer the projected vehicle lifetime in terms of number of flights, the more robust the vehicle must be. A reduction in payload fraction from 0.125 to 0.09 is assumed. In addition, a recovery system must be incorporated into the vehicle. This could be wings and landing gears or parachutes. Also, de-orbit systems must be built into the second stage, and thermal protection systems must be incorporated into both stages. If the RLV is manned, a life support system and, hopefully, a non-destructive abort system must be added. This not only drives up costs secondary to system weight gain, but crew salaries and training costs are incurred. The entire recovery system is assumed to comprise 25 percent of the dry vehicle mass.

In order to deliver the same 1,000 pound payload to LEO, the required RLV is larger than an ELV. The RLV dry mass is 7,333 pounds exclusive of payload and 45,288 pounds of propellant are required to boost the payload to LEO. Total take off mass is 56,399 pounds (a gain almost 16,000 pounds compared to the ELV).

Because the launch system is reusable, fabrication costs are assumed to increase from $\$ 75$ per pound in the case of ELVs to $\$ 400$ per pound for RLVs because of additional labor and more expensive materials used in the RLVs. As discussed previously, aircraft fabrication costs typically run between $\$ 100$ and $\$ 300$ per pound. Given the relative energies involved in space flight and aviation, we believe the fabrication costs used in the model to be optimistic. In addition, prelaunch checkout costs are assumed to increase by 25 percent because of the increased complexity of the RLVs compared to ELVs. The increased complexity comes from the addition of recovery systems for both stages. By designing for simplicity of checkout, checkout costs can be reduced at the expense of increasing $R \& D$. This would increase $\mathrm{R} \& \mathrm{D}$ costs by an estimated 50 percent (to $\$ 75$ million). The magnitude of the increase in R\&D costs is almost certainly optimistic.

Using RLVs adds an additional dimension to the cost analysis. That is recovery and refurbishing. Vehicle recovery cost is assumed to be $\$ 50,000$ per flight. Refurbishing cost is assumed to average two percent of the vehicular structural cost per flight (we include the last flight because the vehicle is likely to be retired due to a failed inspection or incur an expensive post mortem). The refurbishing cost includes labor and spare part or component replacement costs. Table 4

Table 4. RLV Launch Costs over 500 Flights (without interest)

Vehicle Structure per Flight
Propellant
Prelaunch Preparations
Refurbishment Cost
Direct Launch Costs
Amortized R\&D
Amortized Launch Facility
Range Costs
Recovery Costs
Insurance
Indirect Launch Costs
Total Launch Costs
Cost per Pound of Payload
summarizes the RLV costs.

This scenario projects an increase in flyaway costs of 22.9 percent by switching from ELVs to RLVs with comparable payload capacity. The hypothetical program delivers a total of 500,000 pounds to LEO for a program cost of \$923 million. The simulated RLV program uses the same assumptions as the ELV program except as noted.

As is the case with ELVs, the dominant factors in this analysis prove to be range and insurance costs, which result from political, regulatory, and economic factors. For RLVs, the cost of insurance per flight creeps ahead of vehicular structural costs in ELVs, but insurance is also a major component of ELV flyaway costs. In the case of ELVs, range costs plus insurance runs about $\$ 856$ per pound of payload, and increases to $\$ 1,500$ per pound of payload for RLVs because of increased insurance costs. Insurance costs are higher because replacement of the vehicle is insured and the maximum probable loss (MPL) is higher because the RLV is heavier than an ELV. In the long run, launch operations with a proven highly reliable system would reduce insurance costs, but in the near term those high costs are a fact of business life unless the launch company is willing to self-insure for a large share of the liability or invest in studies to demonstrate safety. Self-insuring the vehicle makes sense when vehicle replacement cost is cheap. Self-insuring the vehicle in our model is a much cheaper option. Self-insuring the first party property 
(almost all of the $\$ 540,000$ difference between ELV and RLV insurance costs) pays for a new vehicle every eight flights. For bulk cargo like water where payload does not need to be insured, that gets the price down to $\$ 345$ per pound plus $\$ 620$ per pound in range and insurance costs (including $\$ 40$ per pound in self-insurance for a 0.99 reliability vehicle). Self-insuring first party property frees us from Taylor's second law: "The airplane will be thrown away after each flight." By self-insuring the vehicle, RLVs become cheaper than ELVs according to our assumptions, but may make the vehicle program more expensive to finance. Since self-insuring lowers the insurance to nearly the same cost as for ELVs, we recommend self-insuring the RLV structure. Investing in a design reliability study is another option to lower projected failure rates. ${ }^{16}$

Until a launcher has proven its safety, insurers will still charge large fees for insuring expensive payloads and third party liability. Holding an auction for commercial insurance instead of having a negotiation could potentially reduce insurance costs by 20 percent since 35 percent of commercial insurance premium costs are transactional costs. ${ }^{17}$ Going direct to insurers instead of using a broker may reduce insurance costs an additional five to ten percent. Old fashioned telephone and fax bookmaking leave money on the table as oversubscribed insurance purchases get reduced pro-rata rather than via a premium reduction.

\section{Discussion}

It is apparent that the previous analyses are highly sensitive to some variables: Payload mass, range and insurance costs, and, in the case of ELVs, vehicle production costs. In the case of RLVs, R\&D costs must be higher because of vehicle complexity, designing and testing for multiple flights, and incorporation of recovery systems. Then, recovery, inspection, and refurbishing costs add into the mix.

Flight volume (production run in the case of ELVs or the product of fleet size and vehicle flight lifetime in the case of RLVs) is a very relevant factor. Past history may put various volume projections into perspective. Launch histories are available. ${ }^{18}$ In the 48 years since the first orbital launch in 1957, there have been 4,700 orbital launches in addition to about 22,000 suborbital space (exoatmospheric) launches. Considering a specific commercial vehicle line, 144 Arianes were launched in the 25 years between 1979 and 2003. Only 21 Ariane-5 vehicles were launched in the nine plus years between 1996 and February, 2005.

The effects of using RLVs over a flight lifetime of 100 flights has been discussed, but a 1,000 or more flight RLV remains an unproven concept.

Payload mass is a critical variable. For example, assume that demand for launch services is much higher than in the previous analyses - 100,000 pounds of payload per launch over 500 flights. Because of the economies of scale, the payload fraction as a percentage of dry vehicle weight is increased. In this case, it is assumed to be 40 percent for a large ELV. This is roughly comparable, but slightly better than, the overall figure for the first two stages of the old Saturn-V system. Then, the required propellant mass (assuming $L O x / R P-1$ ) is 1,018,981 pounds per launch of a 100,000 pound payload by a two stage vehicle with 150,000 pounds of dry structure. The assumed ELV fabrication cost was reduced from $\$ 75$ per pound to $\$ 48$ per pound (big things are cheaper by the pound than little things). This results in a vehicle structure cost of $\$ 7.2$ million. Assuming that the launch facility cost is quintupled to $\$ 10$ million for the larger vehicle and that program R\&D is $\$ 400$ million, the model results in a direct launch cost of $\$ 75$ per pound of payload to LEO and indirect costs of $\$ 56$ per pound for a total of $\$ 131$ per pound. This figure includes interest of 12 percent annually over a 10 year program lifetime. Thus, developing an ELV roughly 20 percent of the size of the old Saturn-V system could markedly reduce the direct costs of payload delivery to LEO, but the overall program costs would be about $\$ 6.5$ billion to deliver 50 million pounds to LEO. This appears to be beyond the ability of the alt.space community to fund without governmental participation. For $\$ 1$ billion, we could get a respectable six million pounds to LEO with an RLV for 60 flights versus one half million pounds for our 500 smaller rockets, but $\$ 670$ million in R\&D, vehicle and startup costs is a lot of money to raise and pay interest on. For $\$ 1$ billion of big dumb ELVs, we could get 76 flights and 7.6 million pounds. The maximum capital in this instance would only be about $\$ 418$ million to get started. For the big boosters, insurance is the key issue again. Selfinsuring the $\$ 60$ million RLV will pay for itself in six flights. Self-insured for first party property, the big RLV gets 148 flights for our $\$ 1$ billion - about 2.5 times as many. This analysis leaves out interest, which will be expensive for the big vehicle given the radically lower flight rate (one percent of the small vehicle if payloads are interchangeable).

The production run of an ELV program is also significant. Figure 1 shows the flyaway costs (including 12 percent interest in a 10 year program) for various production runs and payload sizes as discussed previously.

The extreme cases of 500 units produced for payloads of 1,000 and 100,000 pounds were discussed in the text. Increasing production past 1,000 units has very little effect on cost to LEO. A simulated production run of 10,000 units differed from the 1,000 unit case by less than $2 \frac{1}{2}$ percent which is indistinguishable on the graph. If a given 


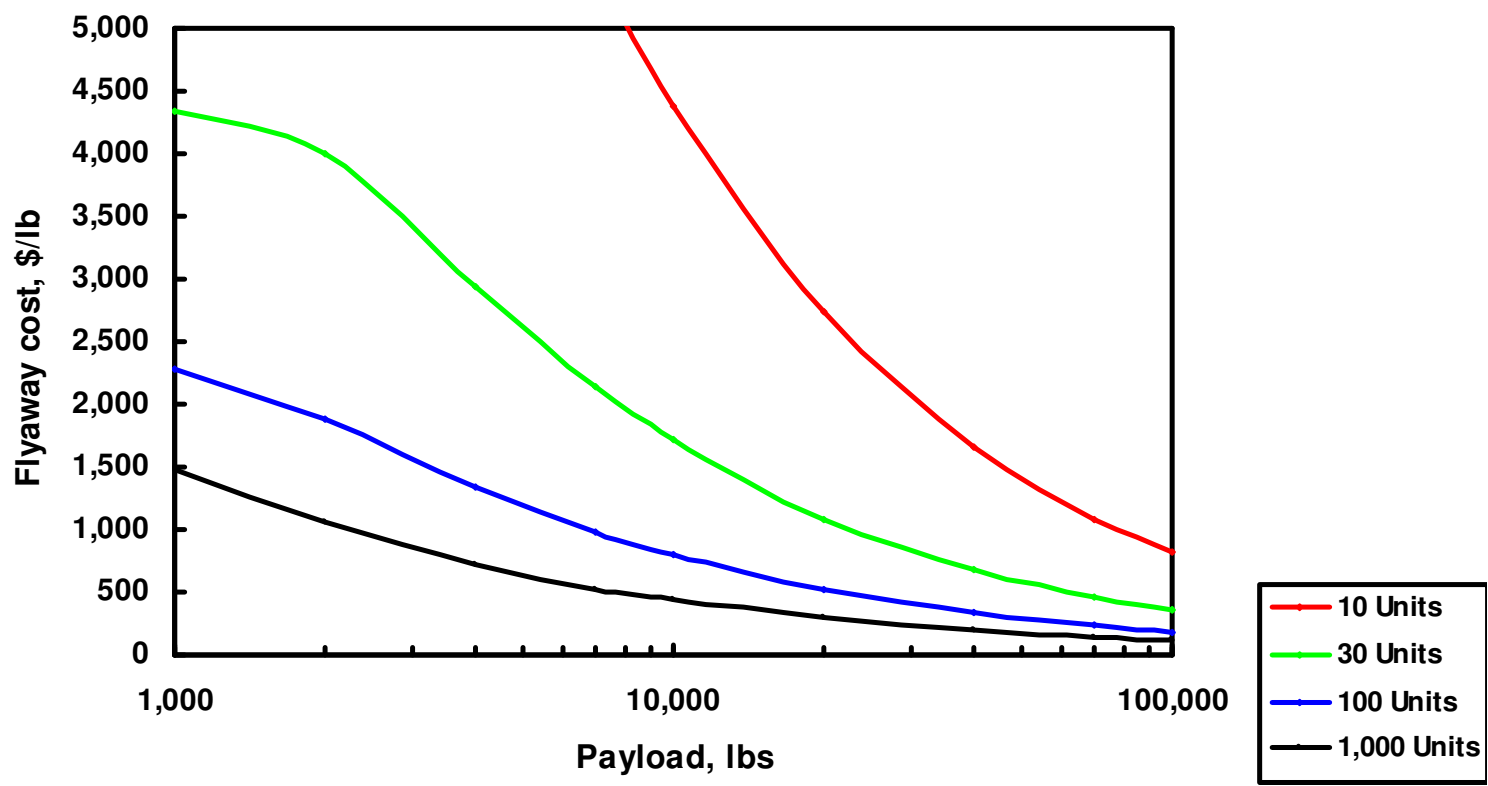

Figure 1. ELV Launch Cost to LEO. Flyaway cost per pound to LEO versus payload size and production run for a 10 year program

production run is planned for amortization of, for example, R\&D cost, and the program is cut prematurely, significant losses can occur. This is a very real business risk.

Very small payload capacity leads to different economics. By going to a 100 pound payload, higher reliability can be demonstrated leading to lower insurance premiums for expensive payloads. The capital requirements for selfinsuring are also lower. A 10,000 flight program would get lower insurance costs after more than 100 successful launches. Smaller payloads might change on-orbit construction requirements or might change bulk cargo economic considerations. Relatively small payloads might be most useful for flights to a manned station such as the International Space Station or a Bigelow Nautilus. There are fixed weight elements regardless of the size of the vehicle such as the avionics and communications. These take a heavy toll on small launchers.
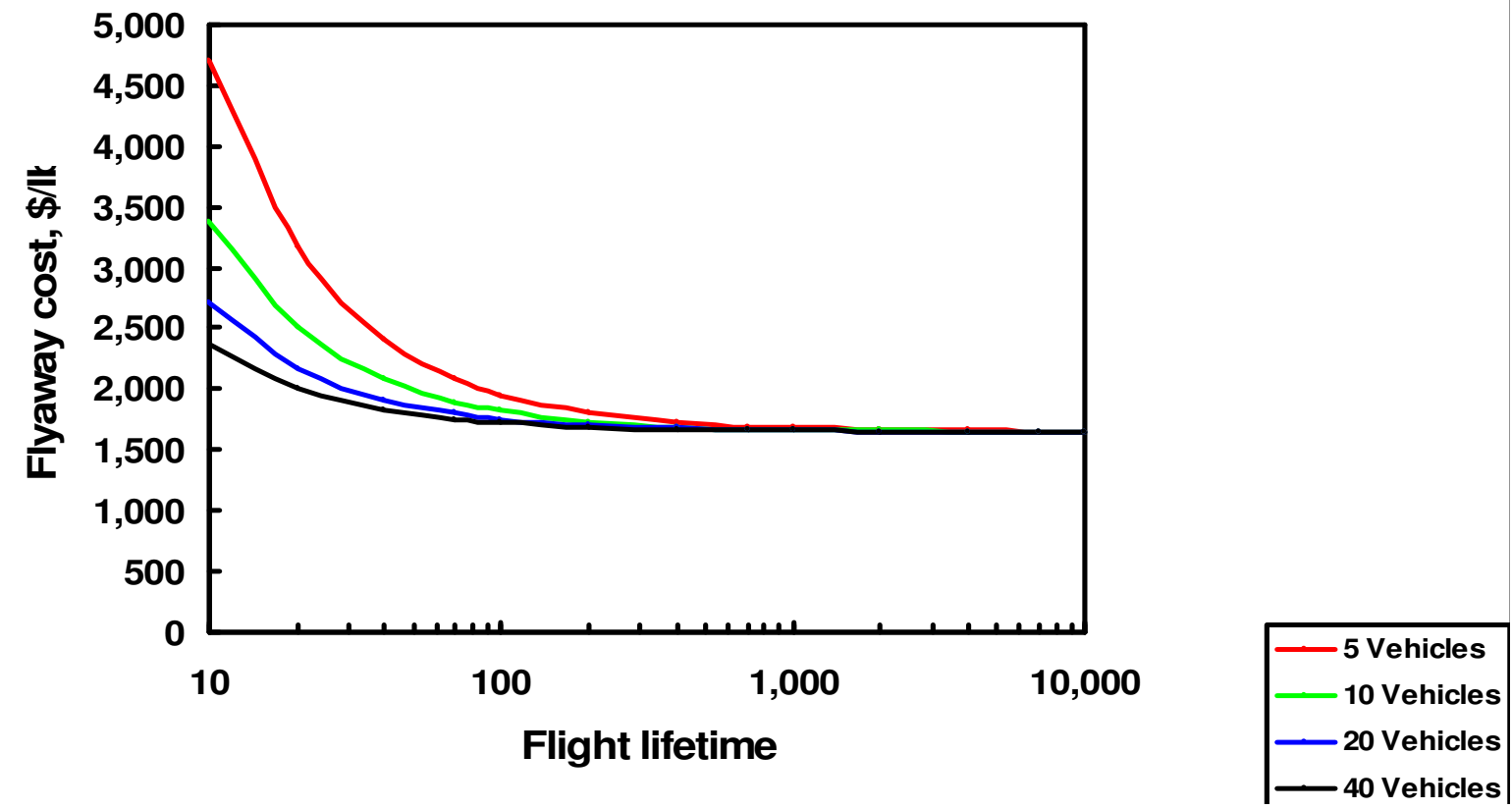

Figure 2. RLV Launch Cost. Flyaway cost versus vehicle lifetime and fleet size for 1,000 pound payloads. 
Examination of the ELV and RLV factors leads to another consideration. The difficulties of designing, building, and maintaining reusable vehicles are well established. The recovery process and required systems for a reusable first stage are potentially much simpler, and therefore less expensive, than for the orbital stage. It appears that the STS got it exactly backwards by having the heavy RLV components in the orbiter and using an expendable external tank and relatively short-lived SRBs. That is, the first stage of a cheap system should be recovered and reflown, and the upper stage(s) should be expendable. Note that this is the approach to be used in the SpaceX Falcon series.

The RLV analysis resulted in some interesting findings. First, payload delivery costs are relatively independent of RLV flight lifetime if the vehicles can be reused more than 100 times. Second, fleet sizes of more than about 20

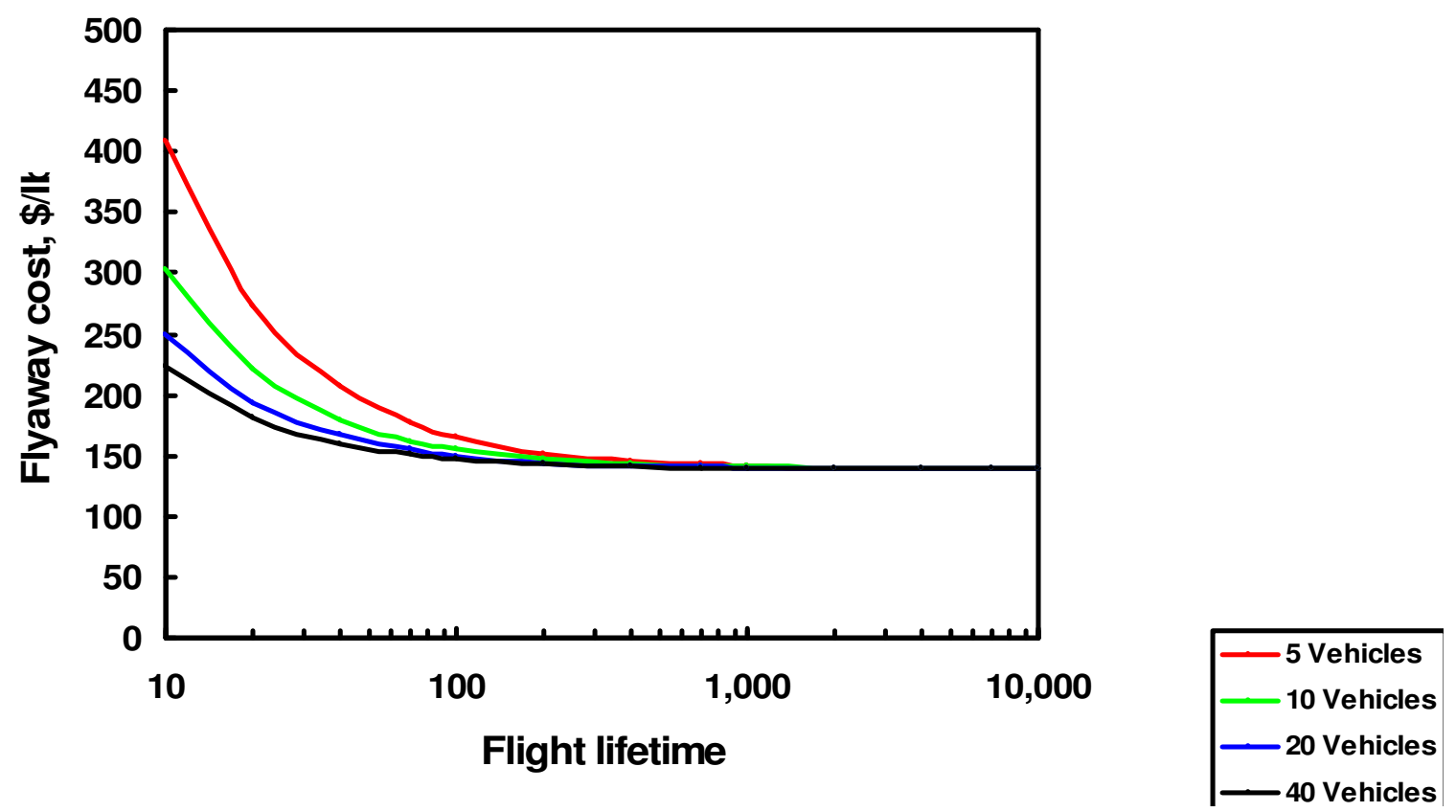

Figure 3. RLV Launch Cost (100,000 lb. payload). Flyaway cost versus vehicle lifetime and fleet size for 100,000 pound payloads.
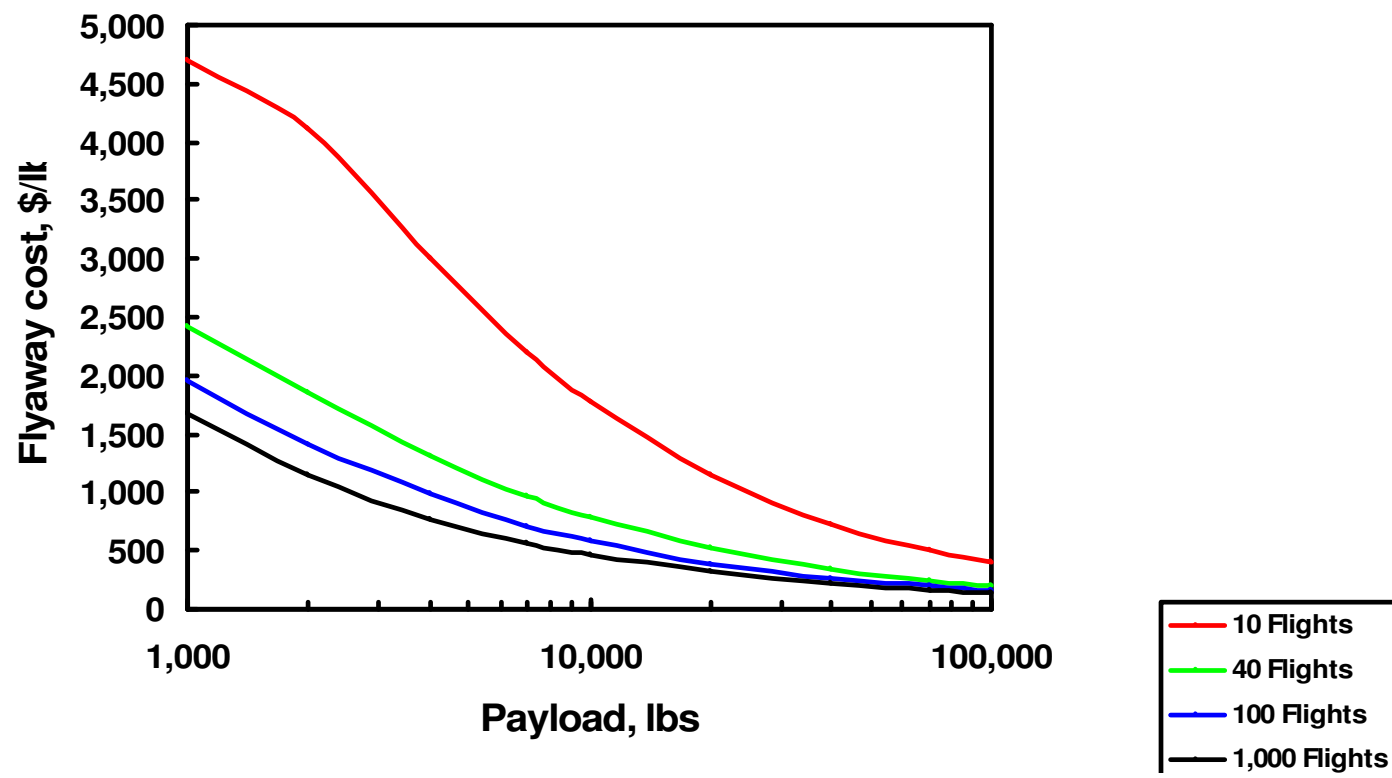

Figure 4. RLV Launch Cost (Fleet Size=5). Flyaway cost versus payload size and vehicle lifetime. 
vehicles do not provide much economy under the analytical assumptions used. As in the case of ELVs, larger payload vehicles lead to significantly reduced flyaway costs per pound of payload. This economy comes at the expense of a significant increase in research and development costs. Furthermore, a large RLV capable of launching 100,000 pounds into LEO is an unproven concept. These findings are illustrated in Figures 2 and 3.

Figures 4 and 5 show the reduction of flyaway costs with larger payload vehicles. These figures also show that the cost improvements with increased vehicle flight lifetime are greater for smaller fleets than for larger fleets.
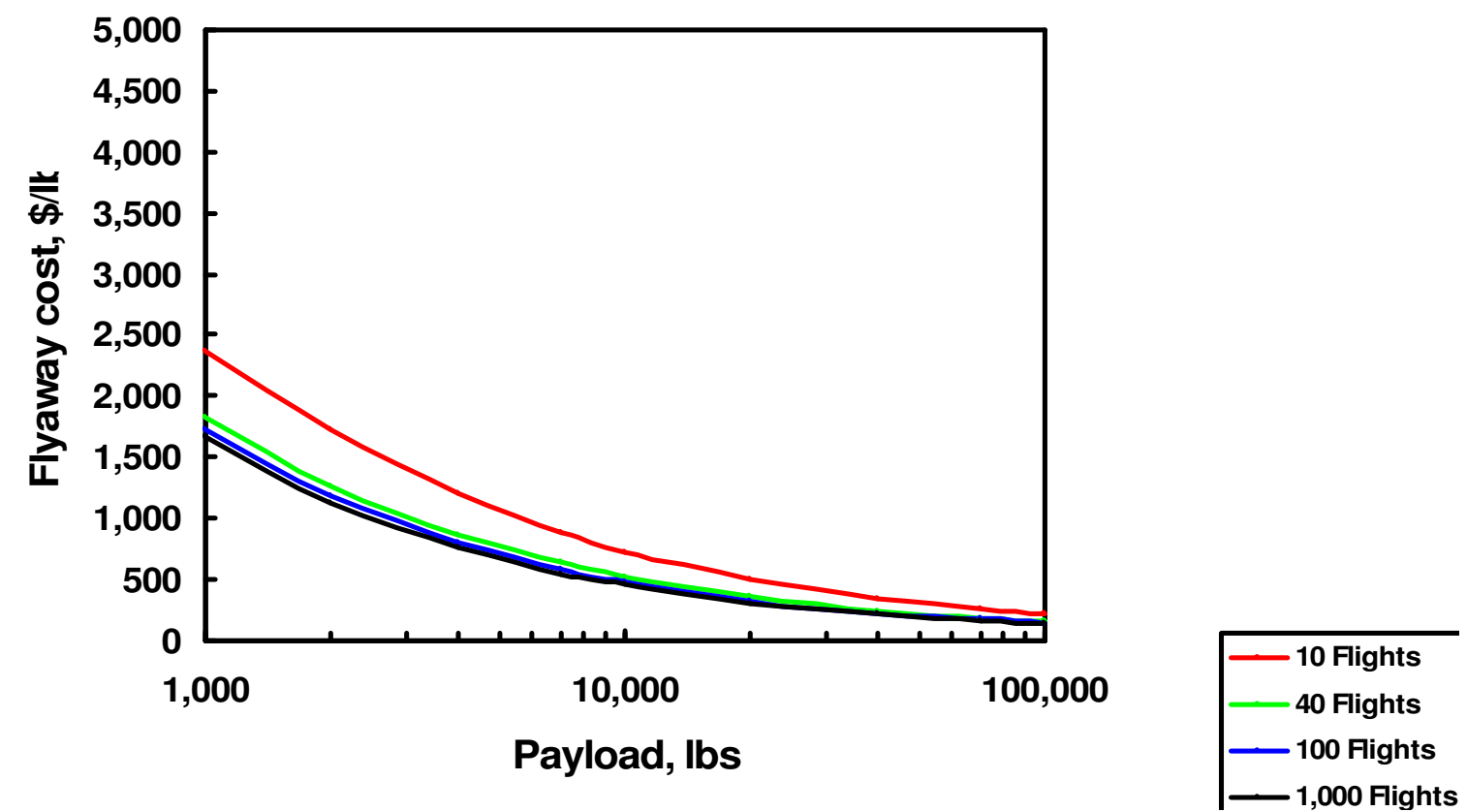

Figure 3. RLV Launch Cost (Fleet Size=40). Flyaway cost versus payload size and vehicle lifetime for a fleet of 40 RLVs.

These analyses are simplified in that they assume that all development costs are amortized over the life of the specific vehicle program. They do not consider the effect of vehicle evolutionary processes on development, manufacturing facilities, or manufacturing costs.

\section{Merging the Rocket and the Payload}

There are several ways to rewrite the rules of the game to make the economics friendlier. If the top stage is the payload, then substantially more mass is devoted to payload. The residual fuel that would normally be unused could be salvaged as could the engine and the fairing. For orbital construction, these parts could be smelted or otherwise recycled. Avionics and communications may be useful as is. If not, clever usage of standard electronic components may allow the avionics to have more general computational uses in space. This approach necessitates a manned orbital facility for payload processing and recycling.

If the structural components are not desirable as payload, it may be possible to modify the structural components to make them into useful payload. For example, if the cargo is water, the cargo could have some sawdust added to it and frozen. At that point, the material, "Pykrete", would have the structural strength of a battleship and could potentially be used to replace a portion of the structural mass of the upper stage. Another possibility might be the use of edible materials for sound or thermal insulation in lieu of a food reserve.

\section{Market Decision-Making and Economic Factors}

Many factors influence market analysis. They include costs for interest, insurance, research, development, and fabrication. In addition, potential market share risks must be analyzed in the context of the anticipated market. Regulatory factors including range costs and insurance requirements must be considered and the associated costs and uncertainties of attempting to influence these factors must be evaluated. These factors will be discussed below. 


\section{A. Interest}

The straight line amortization of R\&D and RLV production costs is a simple approximation to a more detailed business model. $R \& D$ and a large fraction of total production costs must be paid for up front. Unless all flights of the program are conducted in the same year, there will be interest costs to pay if the money was borrowed. If the money was not borrowed, inflation has reduced the value of the dollar received versus the dollars invested and the rate of return on investment has to beat the return for similarly risky investments or else few will want to invest. The cost was calculated for comparable activities at 18 percent annual cost of capital. ${ }^{19}$

If 100 flights are spread out over 8 years, the total of amortization and interest costs for R\&D are approximately the percentage cost of capital times the R\&D cost divided by the number of flights per year (i.e., the principle payment is negligible at the beginning of paying off $R \& D$ ). This is the point where Ted Taylor's first law applies: "There shall be no more than one flight per month." For a \$75 million investment, if 1,000 flights were stretched out to 83 years at one per month, interest would cost $\$ 1,125,000$ per flight. Even in an eight year program, interest expenses or capital costs would require $\$ 7$ million per year on a $\$ 75$ million investment with all of the R\&D costs and production costs incurred prior to the first year. This results in an interest cost of $\$ 56$ per pound. Even for big dumb RLVs launched monthly, the interest would be about $\$ 10$ million per flight, cutting in half the number of flights available for $\$ 1$ billion.

If the interest is compounded every flight at regular time intervals, the relevant relationship is:

$$
A=\frac{\frac{y i}{n} R}{1-\left(1+\frac{y i}{n}\right)^{-n}}
$$

where $A$ is the amount of R\&D principal and interest paid per flight, $R$ is the total R\&D expense, $i$ is the annual interest or discount rate, $n$ is the number of flights in the program, and $y$ is the program lifetime in years.

\section{B. Insurance}

Insurance costs can be reduced by extending the flight testing program. Assume that the vehicle is 99.9 percent reliable-the recommended goal of Henry. ${ }^{9}$ It will be difficult to prove that the vehicle exhibits that reliability level. Insurers are likely to assign a high loss rate until the vehicle has shown many successful flights and multiply that by the maximum probable loss $(M P L)$. Insurers are likely to use something akin to the following equation:

$$
p=M P L\left(\frac{1+f}{1+s}\right) \pi
$$

where $p$ is the premium paid per flight. $M P L$ is the maximum probable loss, $f$ is the number of failures, $s$ is the number of successes, and $\pi$ is the gross profit ratio. If a successful 500 flight test program is conducted, with a $\pi$ of 3, the insurance premium will be about 0.6 percent of MPL. Assuming the MPL is about the same as for Pegasus ( $\$ 40$ million), the third party liability insurance costs would be $\$ 240,000$ per flight. The trouble is that adding 500 flights would cost $\$ 1$ billion mostly because they still need to be insured! As an alternative, a clever study may be able to show that the vehicle is safer than the rate implied by the flight history. ${ }^{16}$ Using direct auctions to obtain insurance may reduce insurance costs by ten to 25 percent.

\section{Research, Development, and Fabrication}

The R\&D costs used in this analysis are almost certainly low. Ashford presents a graph of historic development cost trends against dry vehicle mass for demonstration and prototype aircraft, airliners, advanced aircraft, ELVs and manned spacecraft. ${ }^{20}$ Table 5 compares the $\mathrm{R} \& \mathrm{D}$ costs used in our model compared to those derived from Ashford's data for a prototype (ELV) and an advanced aircraft (RLV).

In current dollars, the research and development cost of the X-15 suborbital rocket plane program was estimated to be $\$ 1.415$ billion. ${ }^{9}$ The cost of the Mojave Aerospace Ventures Space Ship One development is
Table 5. Model R\&D Cost vs. Ashford's Data

\begin{tabular}{lrr} 
& \multicolumn{2}{c}{ R\&D Cost, $\$$ million } \\
Vehicle & Model & Ashford $^{20}$ \\
ELV & 50 & 211 \\
RLV & 75 & 3,316 \\
Large ELV & 400 & 2,549 \\
Large RLV & 600 & 22,051
\end{tabular}


proprietary, but is generally considered to be in the $\$ 20$ million to $\$ 40$ million range.

A similar comparison of our model with established fabrication costs can be made. Table 6 compares the structure or fabrication costs used in our model compared with similar costs of various vehicles expressed in 2004 dollars. ${ }^{9}$

Extrapolation of what is not forbidden by science and technology to what may be possible involves a risk that does not exist with already proven technology. That risk usually results in cost overruns and can occur in relatively mundane activities. The published R\&D cost of the Airbus A380 (approximately $\$ 12$ billion) was between $\$ 1$ billion and $\$ 2$ billion over budget. Keep in mind that the A380 was an evolutionary end product that benefited from the development of prior generations of vehicles. Those prior generations subsidized A380 R\&D to an unknown extent.

The rationale for use of markedly lower vehicle costs than past history would suggest comes from drawing on an existing base of knowledge and experience, using existing technologies and components whenever possible, and running lean organizations rather than organizations based on long histories of cost plus government contracting. Yet, the analysis does not incorporate the cost of maintaining the organization during the R\&D phase or the costs associated with the time during which demand is created or grows to a steadystate level. The analysis also does not account for co-development of a family of vehicles such as Falcon-I and Falcon-V.

As a general proposition, demand increases as cost per unit decreases. Thus, it is reasonable to conclude that launch service demand will increase as price per pound to LEO decreases. Henry concludes that the demand will be relatively inelastic (one percent decrease in price leads to no more than a one percent increase in demand) until cost decreases to around $\$ 1,000$ per pound. Elasticity may occur in the $\$ 1,000-\$ 2,000$ range if orbital tourism materializes, but that market remains unproven. If launch demand proves to be lower than anticipated, an ELV program has R\&D and manufacturing investment at risk. An RLV program has R\&D and already-built vehicles at risk. This risk component can be abated somewhat by keeping the production line open and waiting for additional demand to develop before fabricating more RLVs.

A very important consideration in creating a large scale business with large capital investment is to clearly identify the products or services to be supplied rather than adhering to the "build it and they will come" philosophy of hoping for demand to manifest itself.

\section{The Range Problem and Solution \\ 1. The Range Problem}

Range costs are a large component of the total flyaway costs of launching into orbit. Comprehensive analysis of orbital launch economics shows that cost-effective launch operations are inhibited by high (and perhaps unwarranted) range fees imposed on a launching company for use of a federal range. While the adverse economic impact of range fees has been discussed, those range fees are only a symptom of the underlying disease. The fundamental problem is badly outdated federal launch and operational systems and an infrastructure that will not support high flight rates and commercial operations.

One of the best concise explanations of this problem was provided by James Muncy. ${ }^{21}$ Muncy pointed out that the federal range launch infrastructure was historically developed for missile (IRBM and ICBM) launches. This governmental infrastructure is now maintained, operated, and updated by numerous government contracts. For example, the U. S. Air Force has a contract for operations, another company has the contract to repair broken equipment, another company handles R\&D needs, and still another company handles the procurement of new or replacement equipment. There is no single entity with the authority to make rational economic decisions about the launch infrastructure. The systems are outdated and they are not user friendly. It is challenging if not impractical for a federal range to cycle more than one launch daily. Therefore, the existing federal range launch infrastructure cannot support the commercial launch needs anticipated by private launch companies with their commercially designed rockets and the projected markets.

Discounting range fees does not solve the underlying problem although such discounting may allow a more cost effective economic profile. However, discounting does nothing to modernize the obsolete infrastructure, systems, and management of federal ranges. In contrast, the Mojave, California civilian flight test center and spaceport was designed to test new systems and to utilize modern operating methodologies - something federal ranges are unable to do. The Mojave Air and Spaceport works by establishing a flight and user friendly environment. The federal ranges cannot do this given their legacy and operational profile.

12

American Institute of Aeronautics and Astronautics 
If the goal is to have multiple space flights carrying many passengers, it is essential to run the spaceports or ranges as rational economic entities. It may be possible to privatize and streamline federal range operations, but there is not much interest among the range operating entities or the U.S. Congress to do this. Lower range fees can certainly help a private rocket company, but the federal range will still be operated uneconomically and require taxpayer subsidy.

Pressure to overhaul the federal ranges and launch infrastructure might increase as private spaceports receive licenses for vertical launches. A good example of potential pressure can be seen by examining the developing private range in New Mexico. This range plans to offer private rocket companies state of art launch and range services designed to be commercial from the ground up. When the Southwest Regional Spaceport of New Mexico does begin offering launch services, what will happen to the Florida Spaceport which is stuck in the federal range environment? If Florida wants to compete for private launch business, it will have to modernize. The modernization program will involve far more than just lower range fee pricing or the use of available military facilities at discounted prices. Simply put, without comprehensive modernization, the existing Florida launch infrastructure will not easily support competitive commercial launch services. While Wallops Island and Kodiak Island may be able to launch private rockets with lower range costs, their infrastructure is still not suitable for anticipated commercial operations. There are also issues with these lower cost ranges that relate to orbital mechanics which make them less desirable.

At present, private rocket companies must launch vertically and use a federal range with negotiated range fees, use air launch to avoid federal ranges, attempt to launch from a barge in the ocean, or launch from outside the United States.

As previously discussed, air launch has technical limitations. Furthermore, air launch still incurs range and tracking fees if the launch trajectory intrudes on a federal range. This is precisely the case with Pegasus and the necessity to pay high Vandenberg Air Force Base range and tracking fees even when launching over the Pacific Ocean. ${ }^{8}$

Range fees could be potentially reduced by launching outside of the United States. This is the rationale behind the SeaLaunch concept, which launches in international waters, but use of foreign ranges has a significant regulatory risk: the International Traffic in Arms Regulation (ITAR). This puts regulation of space launch activities involving foreign governments or foreign nationals by U.S. entities under the U.S. State Department. ITAR has proven to be extremely burdensome to academic as well as commercial international collaborations. Technology-related export control issues also exist. At present, Europe and others are many years behind the U.S. in modernizing regulation, but it is entirely possible that the foreign regulatory regime will be more advantageous in the future.

Given the present status of the private rocket industry, it is possible to negotiate lower range fees and operate a vertical launch system profitably since flight rates and demand are still low. However, for the industry to develop and eventually mature, federal ranges and launch infrastructure issues must be addressed. This requires broad modernization of facilities and systems. Furthermore, private spaceports must be established and licensed for sustainable commercial operations. Failure to modernize the federal ranges may result in the development of private spaceports and the ultimate abandonment of federal ranges by private rocket companies.

At present, the impact of range fees must still be considered in business planning. Thus, this paper considers the present impact of the high range fees on potential commercial orbital launch operations.

2. Lobbying to Reduce Range Costs and Obtain Regulatory Relief

National lobbying of Congress and the President in 2004 totaled $\$ 1$ billion. ${ }^{22}$ That may seem like a lot, but it is a pittance compared to the $\$ 2.3$ trillion in Federal outlays. ${ }^{23}$ Congress and the President also pass laws and make executive orders that implicitly subsidize through loan guarantees, forbid activities altogether, impose work and investment rules that implicitly tax certain activities, and establish through the courts and federal agencies how property rights are defined. Thus, it is possible that Congress and the President influence perhaps twice as much of the economy as the Federal Government spends. Given that, $\$ 1$ billion to buy influence on Capitol Hill is surely a bargain. With 589 bills passing both houses of Congress (enrolled) in the 108th Congress, that works out to about $\$ 3.3$ million of lobbying per enrolled bill. Adding in campaign contributions per enrolled bill (about $\$ 400$ million per session for the President-contributed to both parties-and $\$ 900$ million in Congressional campaign contributions) the total is $\$ 7.5$ million per enrolled bill. This is a very reasonable strategy compared to spending more than that on Federal services. One concern is that lobbying and contributions are like an "all-pay" auction where the contribution is non-refundable even if someone else contributes more and seeks the opposite policy outcome. A more equitable system would give refunds to contributors who do not get their policies adopted (otherwise known as honest bribes). We wonder what would happen if people posted prizes that they would pay directly to the Federal Government if they adopted certain policies. 
One interesting lobbying effort would be to get range and tracking costs specified as a tax per pound of payload instead of a flat fee. Until a few years ago, airline taxes were paid as a percentage of revenue. This was considered unfair by the high priced air carriers who were creating losses. A compromise was worked out so that now about half of the fees come from a percentage of revenue and about half come from a flat per segment fee. ${ }^{24}$ For space launches, new entrants with smaller payloads take the role of the regional and hub-bypass airlines and would greatly benefit from range costs being a percentage of what the customer is paying instead of a flat cost per launch.

This should not get too much resistance from the Department of Defense and NASA since range costs are really going from one Federal pocket into another. They will be substantial beneficiaries of lower space access prices. It behooves them to give range access away free like the interstate highway system and the Internet—at least until there is more to tax. Tackling range costs would eliminate Ted Taylor's third rule: "The entire cost of the international airports at both ends of the flights shall be covered by the freight charges." To the extent that lower access prices vastly increase the utilization of the ranges, fixed costs at the range will be spread over more launches and more streamlined procedures will be adopted. The net subsidy from the taxpayer will actually drop considering that they will recoup their tax subsidy in lower launch costs and lower subsidies to the major launchers to keep their production lines open. The ranges have also shown willingness to negotiate range fees so Congressional action may not be necessary to obtain some relief from range costs.

Regulatory relief may be more important than range cost relief. Some launch companies have opted to avoid the national ranges entirely by choosing to air launch or sea launch. Two alt.space CEOs have indicated that they would not use the national ranges even if they were free because of the regulatory burden.

Another opportunity is to seek regulatory relief from unrealistic disaster expenses associated with a maximum probable loss calculation. If there are only 100 flights in a program, the regulatory bar for insurance perhaps should be based on the disaster level that is 95 percent likely to be unseen. That is something akin to the worst disaster in 2,000 flights instead of 10 million flights as presently required by the Federal Aviation Administration. This will only be viable while flight rates remain low. If flight rates really are 500,000 annually, the rules should revert to the one in 10 million standard. The Outer Space Treaty of 1967 requires the Federal Government to pay for any damage in excess of the requirement. Launch firms will likely need to contribute toward a federal pool or identify a federal budget reduction to get the additional implicit liability subsidy into the budget.

The goal of the lobbying should be to reduce flyaway cost for customers in order to increase demand. Higher demand makes existing investments more profitable which benefits firms that have hardware ready to fly. This change will become self-reinforcing once demand becomes elastic (rises more than one percent for each one percent decrease in price). To some extent, favorable regulations allow easier entry which means that the upside of lobbying success must be shared.

\section{E. Potential Market Share Risks}

What does Boeing do if the XYZ Corporation starts making real progress and threatens to take significant market share? The aerospace majors will not sit idly by if a new, highly profitable segment of the launch market develops. They will surely introduce a new launcher that mimics the economic advantages of the market entrant or market leader. Russia is already considering such a response to SpaceX. ${ }^{25}$ SpaceX is also complaining that the U.S. government is hoping to reimburse only its competitors for R\&D to produce rockets similar to its Falcon series. This means that entrants bear all the cost of entry, but only get a portion of the upside of success.

The aerospace majors are not the only threat in this context. NASA has demonstrated a history of attempting to maintain a monopoly in space launch capability. After spending an estimated \$200 million of his own money on an alt.space startup, Andrew Beal made the following comments:

The BA-2C program was the largest privately funded program ever in existence to build a large capacity space launch system. Unfortunately, development of a reliable low cost system is simply not enough to ensure commercial viability. Several uncertainties remain that are totally beyond our control and put our entire business at risk. The most insurmountable risk is the desire of the U.S. Government and NASA to subsidize competing launch systems.... There will never be a private launch industry as long as NASA and the U.S. Government choose and subsidize launch systems. While Boeing and Lockheed are private entities, their launch systems and components are derivatives of various military initiatives. Very little new effort takes place without significant government subsidy, control, and involvement. While we believed that we could compete successfully against the government subsidized [Evolved Expendable] launch vehicles, the characteristics and depth of subsidy for NASA's new initiative as well as its ultimate performance are impossible to determine or evaluate.... We have elected to cease operations. ${ }^{15}$

For years, it was difficult to get past the "my brother-in-law in NASA does not like your plan" problem. This attitude has improved after the Aldridge Commission deliberations, the President's new national space policy, and NASA actually implementing the Vision for Space Exploration. The laugh test is easier to pass after the Ansari XPrize has been won. Mojave Aerospace Ventures has demonstrated a low cost suborbital RLV with a fast turnaround 
between flights-their SpaceShipOne. XCOR Aerospace has demonstrated a low operating cost rocket plane-the EZ-Rocket-at $\$ 900$ per retank. At the end of 2004, HR 5382 became law and encourages suborbital commerce. All of these factors make it more credible that a company can succeed. Nevertheless, it will be difficult. Sean O'Keefe said, before he stepped down as NASA administrator, that if NASA tried to launch a plastic spaceship like Space Ship One, a government investigation would ensue the next day. ${ }^{26}$

\section{The Due Diligence Process}

In capitalizing a startup company, most people would like to follow the Willie Sutton philosophy of going where the money is. As a general proposition, the pool of available investors shrinks rapidly as magnitude of the minimum investment increases. There are very few people on this planet who can potentially write a check for tens of millions of dollars for a high risk investment. Many more could do so for perhaps a million dollars. The U.S. Securities and Exchange Commission (SEC) has fairly stringent rules that regulate the number of private investors who can be approached for a startup company. Those rules also regulate the representations that can be made during the approach. Most state laws either follow the SEC rules by adoption or have even more stringent regulations. In general, other than people who either are or will be actively involved in the company at the management level, socalled "outside" investors must be "qualified." Under SEC rules, a qualified investor must usually have a net worth of at least $\$ 1$ million or income exceeding $\$ 200,000$ the previous 2 years with an expectation of making the same or exceeding that threshold for the current year. If the potential investor files jointly with a spouse, the threshold is $\$ 300,000$ for their joint income. About seven million of those households exist worldwide. Most high net worth people attained that position by carefully watching their spending and investing. They either have, or can buy, the skills required to evaluate a potential investment carefully. High risk or speculative investments tend to comprise a small percentage of the total portfolio of a high net worth investor. Such an investor will generally examine a host of factors associated with a startup before investing.

For example, careful planning by the startup is essential. Having a formal business plan is certainly helpful to the potential investor. A formal business plan also helps management since it forces management to engage in realistic and well-grounded thinking, planning, and decision making. The problems created by the lack of proper planning help foster junk business proposals that find their way to the investment community and thereby damage the credibility of the alt.space community.

NASA Administrator, Dr. Mike Griffin, recently spoke about this very subject:

So the question is in the space business, and I think we can all admit that that type of competition is largely lacking from today's aerospace business. So, for me, as NASA Administrator, the problem is how do we engage that engine of competition more productively so that it can work on behalf of the space business?

I would have to say that for all of my admiration for entrepreneurs-people who take risks and start businesses—nine out of 10 of them fail. They go on to start another business and fail again. One out of 10 of them succeed. They build the business up, and then sell it out to a larger business or take it public and become part of the American industrial landscape.

For all of my admiration for that community—and I have been part of it (I was one of the failures) - I think I would have to say that we are aware that there is a cacophony of voices out there from what we'll call the "non traditional space community" raising their hands saying "I can do it. I can do it. If the government (read Air Force and NASA) would just put some money out available for us - that was dedicated to us - we could perform and you would see."

For the moment, however, based on actual product delivered, I have to consider that mostly noise, with not much signal. Because real competitive businesses develop their own business plan, find their own money, they acquire a team, they produce a product, and they try to see if it will sell. That is what real businesses do. They don't come to the government saying "set aside some money for us. And trust us. And watch us perform." That's not how it works. I guess some people try to do that but it is not a notably successful approach. That is not [in the] the sprit of American industrial and economic competition.

I am literally besieged by entrepreneurs who insist that if I just dump the money into their area we'll get results. OK, maybe so. But I have to deal with the fact that if I gamble money in that direction and product is not delivered then public money has been spent on something which didn't come true. [Moreover] it was money that could have been spent on a higher odds proposition [so] I have to account for why I did that. ${ }^{27}$

In general, there are a number of subjective and objective factors that enter into the investment decision.

\section{A. Subjective Factors}

The coolness factor is not necessarily enough to get significant funding. The current crop of investors has been burned on some sexy space projects. Unless the company has a rich benefactor who wants to spend tens to hundreds of millions of dollars on a cause that may or may not be profitable, space ventures may not be competitive in the current environment. 
Sports teams and racing teams almost all lose money. Yet, year after year, they change hands for positive prices. The explanation of this apparent paradox is that owning a team is cool. Owners are getting substantial non-pecuniary benefits from owning teams. Seeing the way Burt Rutan was affected the coolness of what he is doing, it is not unreasonable to think a little of the coolness rubs off onto the owner.

A second factor at work is that an industrialist investing personal capital may be willing to accept a lower return than a venture capitalist or angel investor. The industrialist may be willing to settle for a risk adjusted eight to ten percent return versus 18 percent for venture capitalists. This implicit subsidy may be more important than subsidizing the losses for a long duration business plan.

What this means is that an orbital vehicle company needs to either have a patron willing to contribute lots of money over the years or must have a competitive advantage so strong that it can participate in a market where many other firms could not survive without a patron. Southwest Airlines has done that. The Yankees make a big profit. There are plenty of chic restaurants that make a profit, but most of them do not. Our hope is that thousands will fly on suborbital flights so that there will be many profitable space firms to invest in, but that is not the case at present.

Other subjective motivations for making relatively small investments in alt.space startups might include helping interesting projects to develop in the hopes of an eventual acquisition of the technology, supporting an individual or small team for a period of time in the hope that an adequate business plan will evolve or in the hope that gaps in the management skill set will be filled.

\section{B. Objective Factors}

If a potential investor is very prudent and allocates his or her investments along rational lines, the alt.space startup must demonstrate how it intends to create a return on investment. That demonstration must include a defined market, a plan to exploit that market, and a cash-flow analysis that supports the anticipated return. The projected return on the potential investment must compete with the opportunity costs of alternative investments. This component of the capital acquisition process is often ignored by the alt.space industry and it shows up in business planning, marketing, financial, and money raising plans. Despite the statistics and what we hear or read in the media, investment capital is a finite commodity! There is competition for financing from countless investment opportunities offering different returns on investment (ROIs), different sets of risk factors, and, of course, different types of investments. For every decision an investor makes, opportunity costs are evaluated and they substantially influence investment decisions.

Briefly, the opportunity cost is nothing more than figuring out what the likely cost of not making an investment would be for making one. For example, were an investor to make an investment of $\$ 100,000$ in an alt.space rocket company promising mature industry results in about five to seven years, a ROI of $4: 1$ over the life of the project estimated at 20 years, with a discounted rate of return annualized at 12 percent, that investor would have to examine other opportunities that could match or out-perform the alt.space investment. The opportunity not taken is the investor's opportunity cost. Unless an investor is absolutely wedded to the specific investment for a variety of subjective reasons, most likely the money will be placed with the most promising opportunity when risk, management, industry, and all other factors are considered. For every decent alt.space investment available today, most investors have multiples of high quality and more likely better performing opportunities for their money in the terrestrial business world. Therefore alt.space companies face extremely stiff competition for investment dollars from multitudes of high quality alternative investments. However, to the very sophisticated investor, the venture capitalist, the professional financier, what constitutes a quality investment opportunity is far more limiting than what the average wealthy investor considers or acts upon. In the end, competing for the "smart" money is even tougher than competing for the "accredited investors" money.

To be specific, a potential investor can simply buy shares in an indexed stock mutual fund and expect to reliably realize long term gains averaging around 10 percent.

That same investor could assume more risk in the expectation of a higher return by buying shares in specialized stock funds, in a diversified set of stocks, or in various real estate transactions.

A concrete example exists in the health care industry. An investor in a closely-held ambulatory surgical center can realize dividend returns on investment averaging 25 percent the first couple of years, 50 percent thereafter, and end up a decade later with a 10 to 15 fold capital gains return on the initial investment. In the latter illustration, the competitive market and regulatory risks are higher, but there are numerous examples of results similar to the above and the demographics of the United States support the market concept.

There are no examples of alt.space startups creating this kind of return. Therefore, the alt.space startup must make a convincing case that it can pull off such a feat if it wishes to attract rational investment money. The alt.space case would have to be even better than a comparable case in a new industry with no negative track record. 


\section{Venture Capitalists}

What about venture capital (V.C.) as a source of investment funds? Many alt.space companies hope that they can readily obtain V.C. capital. An alt.space company will assume that it can readily access this capital pool only if its principals do not understand opportunity cost and the necessary foundation of venture capitalism.

While V.C. pros may take financial positions in companies that they might not normally consider, the alt.space company must still face competition from an extremely large pool of competitive terrestrial opportunities. Furthermore, terrestrial investment opportunities have a long and established history of working with the V.C. industry. Alt space companies do not.

Typically there is potentially a high cost to pay when accepting V.C. money and support. If things do not go according to the business plan, or as it is said, they "head south," company management may have their lives made miserable by the active involvement of the V.C. This may even lead to the forced break up of the alt.space company. To take V.C. money and support, company management must willingly allow the participation of non-space industry team members, a change in the company vision, and V.C. representation on the board of directors. In extreme circumstances, the company must accept replacement of management and the board of directors as well as other restrictive and possibly dramatic changes. How many alt.space company management teams are open to V.C. management influence and takeover if the alt.space company does not perform as promised? How many alt.space management teams understand the true scarcity of capital due to opportunity cost analysis and otherwise competitive market forces among terrestrial business ventures vying for the same dollars? How many alt.space management teams really understand that it is not usually about the rocket science or space objective, rather it is about the return on investment (ROI), payback period, risk assessment for both business and political risks, and internal rates of return (IRR)?

To focus on space and space objectives rather than the fundamentals that make a business venture attractive for capital acquisition is to delay alt.space industrial development. After all, as important as wealthy players and benefactors are, a handful of them with their private investments do not constitute an industrial development program.

An interesting, and temporary, aspect of venture capitalism came to light in February, 2005. National Public Radio's Robert X. Cringely points out that:

$[R]$ ight now, there is in the U.S. venture capital community about $\$ 25$ billion that remains uninvested from funds that will end their life spans in the next 12 to 18 months. If the V.C.s return those funds to investors they'll also have to return $\$ 3$ billion in already-spent management fees. Alternately, they can invest the money-even if they invest it in bad deals-and NOT have to cough-up that $\$ 3$ billion. So the V.C.s have to find in the next few months places to throw that $\$ 25$ billion. ${ }^{28}$

Many of the V.C.s' covenants prevent them from investing outside a specific industry, but even if a few percent of that money flows into alt.space, it could nearly double the capitalization of the industry.

\section{Reality Versus Speculation}

Most forecasts and projections used by those raising capital and promoting "the cause" use mature launch industry statistics to make their business and investment case. They report this information as if it exists now or that it would exist were it not for an abusive regulatory system, NASA, pig-headed capitalists, or possibly the full moon on October 31st! The reality is: We do not have a mature industry although we are almost 60 years into orbital rockets - considerably longer if we include the Chinese development of rockets for fireworks. Yet, we are not at the point where we have the spaceship analog of the DC3 when discussing the aviation industry. A reasonable and plausible plan to move from where the industry is today to the mature industry we all desire is omitted from the common and usual claims. This omission can lead to problems in accepting performance, cost, and flight rate assumption parameters for any proposed space vehicle.

A specific example can readily demonstrate this disconnect between the theoretical future and the attainable present. Consider the Japanese space tourism RLV, the Kankoh-Maru. The Kankoh-Maru is a hypothetical SSTO vertical takeoff and landing passenger vehicle which would be capable of orbital operations leaving from routine airports around the world. It would have commercial airplane-like economies of scale and safety. To understand how this vehicle can accomplish these impressive results, it is necessary to look at the model used, paying particular attention to the underlying assumptions. Kankoh-Maru was selected for this analysis over others because it clearly demonstrates the challenge facing entrepreneurial and new rocket engineers and builders. Since virtually everything about the new rocket design is speculative, unknown, or untested, the variables supporting the underlying assumptions can be difficult to accept. Any of the potential new rocket designs could have been used for this model but so much information was available regarding the assumptions used for Kankoh-Maru. We use it for discussing the need to have a solid foundation underlying the assumptions for any business plan, not just a new rocket or launch vehicle. 
Most of the information available about the Kankoh-Maru-its design, specifications, economics, and flight characteristics—can be obtained from the excellent Spacefuture website. ${ }^{29}$ For this analysis, data come from a 1997 paper by Collins and Isozaki. ${ }^{30}$ We thank the researchers for making this information public.

The successful flight and operations profile for the Kankoh-Maru is to be realized at a growth rate of 2,400 flights per year per year with eight Kankoh-Maru vehicles manufactured per year up to a fleet of 50. Each vehicle would have a 10 year or 3,000 flight useful life. The program would fly an additional 100,000 passengers per year over the 8 year growth phase. To facilitate this outcome, the production growth rate of cryogenic propellants would be approximately 1,000,000 tons per year per year, the number of engine spare part replacements kits would increase by 288 sets per year per year up to 1,800 sets per year. At that time, there would be a fleet of 50 operating Kankoh-Maru RLVs. It is further assumed that the motors will need overhauled after every 100 flights. If or when operations attain this level, the desired operational cost goals would be realized.

We will examine the assumptions which support the claim that Kankoh-Maru can dramatically lower the cost to orbit and providing orbital flights to space tourists for $\$ 20,000$ per passenger.

Despite the Collins and Isozaki paper being written in 1997, we are no closer to having an orbital RLV, let alone having any vehicle approaching the operating profile cited in this paper. In fact, we have no orbital RLVs currently flying at any price. We have no large rocket engines that can fly 100 times without an overhaul. We have no space vehicles of any type capable of using commercial or passenger airports now that Space Ship One is headed to a museum. There are a few planned vehicles of this type in various stages of initial development and flight testing. We have no vehicle or class of vehicles capable of anything close to achieving 300 flights per year per vehicle. Despite general space tourism market surveys, it is not certain we have demand for 2,400 orbital flights annually of any type. We are not confident that we have a demand for 2,400 suborbital tourist flights even though they seem to be almost around the corner. So how do we go from where we are today to something on the order of the Kankoh-Maru program? That is, how do we go from the beginning stage of space transportation vehicle development, which is where we are today, to the projected Kankoh-Maru program or one similar to it which suggests a mature industry with sustainable, growing markets and demand?

Collins and Isozaki do provide a basic path to enable the results that they suggest are possible with the KankohMaru. Their multi-phase plan as outlined in their paper is still speculative. The end results of a successful development and operational program for this RLV program are equally speculative. So while the results suggested by a successful development program, which could lead to a mature industry capable of supporting a fully developed and tested Kankoh-Maru RLV are promising, we are a long way from showing substantial progress leading to creating such a vehicle or vehicles of its class, let alone realize its suggested commercial benefits.

Any proposed orbital RLV development plans are still based on favorable speculative assumptions because that is the nature of this or any other nascent industry. Evaluating the plausibility of assumptions is required. Since we are still engaged in speculation to a large degree, this is not an easy task. One approach which could reduce questioning of RLV assumptions would be for engineers and rocket designers to work hand and hand with financial types in an interdisciplinary approach. This would function the way an architect has to pay attention to and work with a builder or contractor in an iterative process to develop realistic cost estimates. It does the architect little good to have a fabulous design that is so costly it never gets built or exhausts the construction budget before completion. In our opinion, many of the activities now supporting various vehicle designs and concepts require additional financial discipline. Such discipline will certainly lead to more credible assumptions, even in this developing industry where so much remains unknown and unable to be verified.

The bottom line is that a program like the Kankoh-Maru and virtually all planned orbital RLVs rely on assumptions based on assumptions which are based on more assumptions. At some point, one has to ask the question, "Where is the foundation in this process?" What is lacking is a solid, reality-based, plausible scenario to take us all the way from today to the flight and market goals and objectives projected for the Kankoh-Maru at some point in the future. Without a credible program to do this or to even point the way, we are confined to wanting to believe, but not certain of the foundation supporting our belief. This same argument can apply to the rhetoric used in much of what today passes for the claims of business ventures, rocket concepts, or startups going for the brass ring in rockets or space transportation vehicles.

Space enthusiasts often cite the expectation that launch cost to LEO can drop below the magical value of as little as $\$ 100$ per pound. That implies a fully mature industry in which large RLVs have lifetimes of thousands of flights and short turnaround times between flights. Such airline-like characteristics simply do not exist. Given the lack of demonstrated development of such vehicles, the present regulatory environment, and the large capital investment required, creation of such a fleet of RLVs in the relatively near term is not likely to occur without a strong national imperative and government participation in funding. 
The current demonstrated technology in which multiple burn high thrust rocket motors have lifetimes of a few tens of minutes of burn time and few tens of starts compares to the very early jet engines that were replaced after a few hours of operation. Until we see reliable reusable rocket engines, our 4th law will apply, "Jet engines will have narrow safety margins and will not run more than a few hours without major overhaul." Spacecraft structures capable of thousands of flights have not been developed. We do not see a rapid direct path to such a mature launch industry other that via a relatively slow evolutionary process similar to that of the aircraft industry over the last century.

\section{E. Polluting the Pond}

Many in the alt.space business, including the startup and entrepreneurial management teams and those raising money for their ventures, come close to preaching that there are no scientific or engineering limitations that prevent the development and operation of cost effective RLVs. The often unstated assumption is that this is based on current off the shelf technology. The focus here is on the need for those working to develop the alt.space industry to become comfortable with reality so that efforts to move forward, through either evolution of existing technology, or the development of completely new and different technology can occur. The industry is not helped by denial and posturing that there are no systemic limitations with chemical rockets. To do so seems to be working for the status quo or even supporting a backward stepping industry rather than facilitating its efforts to move forward. While this is not intentional, it is the likely result of accepting an outcome that is not grounded in reality.

An efficiently run private sector rocket company can achieve cost reduction with chemical rocket systems over that of a large aerospace company working off of government contracts. We are nearing the point of reaching the marginal cost with chemical rocket engines. In economics, the term marginal cost refers to cost of producing an additional unit of output which is a function of the costs of the additional units of input needed for the production of that additional output unit. As savings are realized by the more efficient company, the company moves rapidly toward the marginal cost point for developing a cost effective chemical rocket. It has not been possible to demonstrate that incurring marginal costs with chemical rockets will achieve low cost LEO. It does no good for this developing industry and would-be startups to promote as possible that which is not. Furthermore, to invest irreplaceable and invaluable assets such as time, management skill, and finite capital into what is not plausible is to squander precious resources. This leads to failure at worst, and excessively costly success at best. It would be wiser to understand the realities of what the industry faces and undertake the production of goods and services that can achieve success notwithstanding the limitations. One could then invest the skill, time, and capital into finding plausible ways to accomplish the stated goals of low cost LEO access. In fact, revenue from businesses that can be sustained despite the limitations can be used to fuel R\&D for the new products that can actually spur the development of the new space industries that are cited as possible once low cost space access is achieved.

However, to the degree that resources and rhetoric remain unrealistically committed to that which has real physical, engineering limitations or political, economic ones such as range cost and insurance, the development of new space industries is adversely affected.

In business planning and forecasting, projections and conclusions are only as good as the foundation upon which they are built. Even with data based on a solid foundation, projections and forecasting are far from perfect. Consider an econometric model of the U.S. economy using hundreds or thousands of variables with years of factual data used as input. Still, the conclusions presented by econometric models are not always on target. Econometric modeling is not based on consensus, poor quality data, or wishful thinking. Consider what it would mean if econometric modeling was based on assumptions which had no basis in reality.

To further illustrate the need for a solid foundation for the assumptions used in reaching a conclusion, Michael Crichton recently used the famous Drake Equation for estimating the potential existence of extraterrestrial life in the solar system in a lecture delivered at the California Institute of Technology (Caltech). Although Dr. Crichton's point was to illustrate the difference between science and speculation, it also applies to business. Crichton explains that:

[The Drake Equation] can have any value from 'billions and billions' to zero. The problem, of course, is that none of the terms can be known, and most cannot even be estimated. The only way to work the equation is to fill in with guesses. And guesses - just so we're clear-are merely expressions of prejudice. Nor can there be 'informed guesses.' If you need to state how many planets with life choose to communicate, there is simply no way to make an informed guess. It's simply prejudice. ${ }^{31}$

Thus, guessing or estimating all the variables does not lead to science. To apply this concept to business, guessing will lead to whatever numbers are put in the pro forma or ROI forecasts, but will not necessarily lead to reality.

In business and finance, using information that is not grounded in reality, that is speculative at best, or that is exaggerated, while possibly producing a desired result and conclusion, does not make the result or the conclusion accurate, useful, or valuable. However, if the person being presented with the information does not know the 
weakness of the underlying assumptions, then the end result is skewed toward the irrelevant end of the spectrum even more. As these conclusions, without being based on a sound foundation, circulate through various aspects of the alt.space community, the financial markets, specific business and industry sectors, damage is done. This damage is felt the most by those that are striving for accuracy, reality, and high quality business and strategic planning for their ventures. As investors get burned by having bought into the rhetoric, the word spreads and other investors become sensitized to the fact that much of what may be said about alt.space business investments and opportunities is nothing more than speculation at best, garbage at worst. To the degree that junk and inflated rhetoric filters into the traditional banking, venture capital, and investor domains, the odds of the damage showing up as difficulties for those seeking capital and higher capital acquisition costs for the legitimate business opportunities in alt.space multiply demonstrably. Until the industry does a better job of toning down its rhetoric and extravagant business assumptions, it will continue to be bound by our 5th law: "Aviation management will consistently avoid high quality business planning and will ignore the technical and financial realities related to their industry."

\section{F. Investor Concerns}

In addition to potential return on investment in the context of opportunity costs, what are some of the concerns of potential alt.space startup investors-particularly angel investors?

The fundamental concern is whether or not the existing team can accomplish its stated goals. In order to do so, the team must have a realistic definition of those goals. That means not adhering to the "build it and they will come" philosophy. Instead, the team must specifically define its target market or markets by depth and size in the business plan. If the existing team does not have the depth to do so, it must be willing to recognize that shortcoming and have a plan to recruit the talent required to do so.

The courtship of the potential investor is highly variable. Ideally, it should be conducted in a business-like manner. That means, first and foremost, having a convincing business plan. Risk factors that alert a potential investor to a lack of business acumen in the startup team include dismissal of other disciplinary contributions. Many alt.space startups project the attitude, rightly or wrongly, that they are great engineers and don't need a finance person's help. Yet, they may not understand what "present value" means. Even worse, denigration of other startups or potential competitors displays a destructive, unhealthy attitude to the potential investor.

The time to implement adequate financial and management data tracking systems is before expanding into a prolonged technical development process. During a period of expansion, implementing these systems is an additional headache. This also holds true for staff recruiting and expansion as well as capitalization. If the principals casually talk about staff expansion by orders of magnitude, that is a red flag for the potential investor. "There are 4 of us, but we will hire 50 engineers and technicians the month after we raise the money and can fly within two years" does not pass the credibility test of the experienced investor. A team component must have a track record demonstrating the ability to raise capital or the offering should contain an escrow provision. The offering should obligate the team to providing at least quarterly properly annotated financial summaries to angel investors. If it does not, and if the potential investor senses even a hint that the principals are not familiar with, and do not intend to carefully adhere to, securities rules, he or she should pass on the offering. Other financial considerations that alert the potential investor to an unrealistic business attitude is a balance sheet with intellectual property dominating the asset list, a failure to convincingly demonstrate an expected ROI that is competitive with alternative investments, and no realistic budget allocation for regulatory compliance, licensing, etc.

Although many angel investors in startups are willing to overlook significant deficiencies if they expect that the management team can grow or mature into business-like behavior, any hint of the following will generally result in the potential investor forgoing the investment:

1) The principals cannot understand why the coolness factor is not enough to get capital.

2) The principals display a casual attitude about angel investors and shareholders and show no inclination to use the skills of those investors in the management of the business.

3) The organization displays obsessive secrecy about plans, markets, progress to date, etc.

4) The corporate web site uses the present tense to describe concepts without associated hardware as in "We offer cheap access to LEO," when current reality is "We eventually hope to offer cheap access to LEO." This is akin to vaporware in the software industry.

5) The announced corporate goals expand more rapidly than milestone achievements. For example, the first announced goal of achieving LEO is renounced in favor of the goal of rescuing the Hubble telescope without ever having achieved LEO.

6) The corporate team spends disproportionate energy on news releases and interviews about their goals rather than working quietly to make those goals happen. News coverage is seductive and can be a gigantic sink 
for creative energy best expended on the business. A corollary of this observation is that management energy spent on logo shirt design is energy not spent on the business.

\section{Conclusion}

The critical factors in making RLVs cheaper than $\$ 1,000$ per pound is lobbying, negotiating, or exiting to lower range fees, lobbying to lower liability insurance standards, auctioning payload and liability insurance, and selfinsuring the vehicle. Even the best engineering will not help if $\$ 1,000$ to $\$ 1,300$ per pound is consumed by range fees and insurance. The flight program must be numerous enough to recoup R\&D costs and short enough that interest costs on vehicles and R\&D do not swamp profits. The ultimate reliability of the vehicle must be high to lower insurance costs and increase demand, but not so high as to unduly impact R\&D and production costs and utilization levels. The lobbying involves nontechnical issues and the outcome is far from assured.

Finally, a successful private-sector suborbital industry based on solid business, planning, financial, accounting, marketing, and management operations can lead to the same type of success for orbital space access. Streamlining operations based on business know how should not be discounted because entrepreneurs doing this in the suborbital industry will be successful businessmen. When success can be demonstrated in the suborbital industry and starts evolving into low cost orbital space access, there will be verifiable track records and established management teams. These are the basics needed to attract capital and assure success.

Thus, it is not impossible to achieve launch costs of less than $\$ 1,000$ per pound, but demonstration will require more than a snapshot of a mature industry. Until there is a major change to the rules of the game, inelastic demand will provide incentives to stay in the status quo. Getting to the required flight rate for profitability may take too long to be commercially feasible.

Any governmental policy maker, corporate CEO, or entrepreneur who believes that the current economic state of affairs in space transportation is amenable to profitable commercial enterprise (outside of very limited niche markets) is sorely mistaken. ${ }^{9}$

Nevertheless, we believe that an evolutionary process from commercial suborbital vehicles to commercial orbital vehicles with capability of carrying passengers is feasible given realistic planning and financial goals and careful definition of the market. Ultimately, this evolutionary process will convert us into a space-faring society.

\section{Appendix 1: Propellant Costs}

Table 10. Propellant Cost.

Propellant Cost, $\$ / 1 b$

Baseline Model KSC Other

Kerosene $\quad 0.308(R P-1) \quad 0.278(R P-1) \quad 0.512($ Jet-A) [Edwards]

$\begin{array}{llll}\text { LOx } & 0.298 & 0.064 & 0.187 \text { [Las Vegas] }\end{array}$

$\begin{array}{lll}\mathrm{LH}_{2} & 1.400 & 1.30\end{array}$

The baseline models used LOx costs obtained from General Distributing Company in Billings, MT. Those costs included all taxes and transportation fees. $\mathrm{LH}_{2}$ costs came from DOE. ${ }^{12}$ Obviously, propellant costs will vary with quantities purchased and associated shipping costs and taxes.

Other costs for fuel in January, 2000 delivered to Kennedy Space Center (KSC) were obtained from Henry. ${ }^{9}$ Those costs should be inflated by about 25 to 30

percent to bring them to the present. Since they were for governmental purchases, they did not include taxes paid in the private sector.

Finally, Jet-A fuel cost was obtained from the Edwards Jet Center in Billings, MT on March 9, 2005. Jet-A is very similar to $R P-1$ and was used as a surrogate.

April, 2005 telephone quotes for $L O x$ were $\$ 0.187$ per pound in Las Vegas, Nevada and $\$ 0.295$ per pound in Mojave, California for 160 liter quantities.

\section{Appendix 2: Baseline Models}

Table 7 shows the analytical results of the ELV and RLV baseline models. In this table, the red values are input and blue values are output. Numbers for 1,000 pound payload, 10,000 pound payload, and 100,000 pound payload programs are included in the analysis.

The R\&D and Facility Amortization values include finance charges that are not included in the tables presented within the paper. 
Table 7. LEO Cost Spreadsheet.

\begin{tabular}{|c|c|c|c|c|c|c|c|}
\hline & ELV & RLV & MedELV & MedRLV & Big ELV & Big RLV & \\
\hline Circular LEO Velocity & 7,905 & 7,905 & 7,905 & 7,905 & 7,905 & 7,905 & $\mathrm{~m} / \mathrm{sec}$ \\
\hline Drag \& Loss Fraction & $15 \%$ & $15 \%$ & $15 \%$ & $15 \%$ & $15 \%$ & $15 \%$ & pct \\
\hline Actual Delta-V to LEO & 9,091 & 9,091 & 9,091 & 9,091 & 9,091 & 9,091 & $\mathrm{~m} / \mathrm{sec}$ \\
\hline Stages & 2 & 2 & 2 & 2 & 2 & 2 & \\
\hline Exhaust Velocity & 2,798 & 2,798 & 2,798 & 2,798 & 2,798 & 2,798 & $\mathrm{~m} / \mathrm{sec}$ \\
\hline Fuel Density & 0.810 & 0.810 & 0.810 & 0.810 & 0.810 & 0.810 & $\mathrm{~g} / \mathrm{cm}^{3}$ \\
\hline Oxidizer:Fuel Wt Ratio & 2.24 & 2.24 & 2.24 & 2.24 & 2.24 & 2.24 & ratio \\
\hline LOX Density & 1.140 & 1.140 & 1.140 & 1.140 & 1.140 & 1.140 & $\mathrm{~g} / \mathrm{cm}^{3}$ \\
\hline Mass Ratio, Stage & 5.076 & 5.076 & 5.076 & 5.076 & 5.076 & 5.076 & ratio \\
\hline Propellant & 0.8030 & 0.8030 & 0.8030 & 0.8030 & 0.8030 & 0.8030 & fraction \\
\hline Payload:Total Dry & 0.125 & 0.090 & 0.263 & 0.195 & 0.400 & 0.300 & fraction \\
\hline Recovery:Total Dry & 0.000 & 0.250 & 0.000 & 0.250 & 0.000 & 0.250 & fraction \\
\hline Payload Mass & 1,000 & 1,000 & 10,000 & 10,000 & 100,000 & 100,000 & $\mathrm{lb}$ \\
\hline Other Structural Mass & 7,000 & 7,333 & 28,095 & 28,462 & 150,000 & 150,000 & $\mathrm{lb}$ \\
\hline Recovery System Mass & 0 & 2,778 & 0 & 12,821 & 0 & 83,333 & $\mathrm{lb}$ \\
\hline Total Dry Mass & 8,000 & 11,111 & 38,095 & 51,282 & 250,000 & 333,333 & $\mathrm{lb}$ \\
\hline Propellant Mass & 32,607 & 45,288 & 155,273 & 209,022 & $1,018,981$ & $1,358,641$ & $\mathrm{lb}$ \\
\hline Gross Take Off Mass & 40,607 & 56,399 & 193,369 & 260,304 & $1,268,981$ & $1,691,975$ & $\mathrm{lb}$ \\
\hline Fuel Cost & 0.308 & 0.308 & 0.308 & 0.308 & 0.308 & 0.308 & $\$ / \mathrm{lb}$ \\
\hline LOX Cost & 0.298 & 0.298 & 0.298 & 0.298 & 0.298 & 0.298 & $\$ / \mathrm{lb}$ \\
\hline Propellant Cost & 0.301 & 0.301 & 0.301 & 0.301 & 0.301 & 0.301 & $\$ / \mathrm{lb}$ \\
\hline Vehicle Flight Lifetime & 1 & 100 & 1 & 100 & 1 & 100 & count \\
\hline Fleet Size & 500 & 5 & 500 & 5 & 500 & 5 & count \\
\hline Program Lifetime & 10 & 10 & 10 & 10 & 10 & 10 & years \\
\hline Interest Cost & $12.00 \%$ & $12.00 \%$ & $12.00 \%$ & $12.00 \%$ & $12.00 \%$ & $12.00 \%$ & $\% /$ year \\
\hline Max Probable Loss & $16,919,882$ & $23,499,836$ & $80,570,867$ & $108,460,782$ & $528,746,313$ & $704,995,085$ & $\$$ \\
\hline Structure Cost & 75.00 & 400.00 & 61.50 & 325.00 & 48.00 & 250.00 & $\$ / l b$ \\
\hline Structure Cost & 525,000 & $4,044,444$ & $1,727,857$ & $13,416,667$ & $7,200,000$ & $58,333,333$ & $\begin{array}{l}\$ / \text { vehicle } \\
\%\end{array}$ \\
\hline Flight Refurbish Cost & $0.0 \%$ & $2.0 \%$ & $0.0 \%$ & $2.0 \%$ & $0.0 \%$ & $2.0 \%$ & Structure \\
\hline Prelaunch Prep Time & 100 & 125 & 300 & 375 & 500 & 625 & $\mathrm{hr}$ \\
\hline Prelaunch Prep Rate & 50.00 & 50.00 & 50.00 & 50.00 & 50.00 & 50.00 & $\$ / \mathrm{hr}$ \\
\hline Structure Cost & 525,000 & 40,444 & $1,727,857$ & 134,167 & $7,200,000$ & 583,333 & $\$ /$ flight \\
\hline Propellant Cost & 9,818 & 13,636 & 46,751 & 62,934 & 306,801 & 409,068 & \$/flight \\
\hline Flight Refurbish Cost & 0 & 80,080 & 0 & 265,650 & 0 & $1,155,000$ & \$/flight \\
\hline Prelaunch Prep Cost & 5,000 & 6,250 & 15,000 & 18,750 & 25,000 & 31,250 & \$/flight \\
\hline Direct Launch Cost & 539,818 & 140,410 & $1,789,608$ & 481,500 & $7,531,801$ & $2,178,652$ & \$/flight \\
\hline Direct Launch Cost & 539.82 & 140.41 & 178.96 & 48.15 & 75.32 & 21.79 & \$/lb LEO \\
\hline Program R \& D & $50,000,000$ & $75,000,000$ & $225,000,000$ & $337,500,000$ & $400,000,000$ & $600,000,000$ & $\$$ \\
\hline Launch Facility Costs & $2,000,000$ & $2,000,000$ & $6,000,000$ & $6,000,000$ & $10,000,000$ & $10,000,000$ & $\$$ \\
\hline Program Lifetime & 500 & 500 & 500 & 500 & 500 & 500 & flights \\
\hline
\end{tabular}

In Table 8, values for an air-launched ELV $(\boldsymbol{A C}+\boldsymbol{E} \boldsymbol{L V})$ are presented without the associated costs of the launching aircraft. This program bears some similarities to the Pegasus vehicle, although the maximum probable loss figure for the Pegasus is closer to $\$ 40$ million. In this analysis, the maximum probable loss was computed at $\$ 417$ per pound of fully fueled vehicle with payload in place. Range costs for the air-launched vehicle were arbitrarily set to $\$ 200,000$. Keep in mind that if the vehicle track up to orbit intrudes on a national range, range costs will be incurred.

PseudoFalcon-I represents a program that exhibits some similarities to the SpaceX Falcon-I project, and PseudoFalcon-V represents a program similar to the Falcon-V. Range costs for the Falcon series were negotiated and include an unknown component of public subsidy. Note that the Falcon series has yet to fly successfully and the first test flight of Falcon-I is currently scheduled to take place in September, 2005. By commissioning a reliability study, SpaceX was able to negotiate lower insurance costs based on assumed reliability of similar vehicles. In addition, the first few manifested flights carry uninsured government payloads.

The green values represent computed risk-based insurance premiums as an alternative to traditional launch insurance premiums based on assumptions of reliability shown in the table. 
Table 8. Air Launch and Pseudo Falcon Spreadsheet.

\begin{tabular}{|c|c|c|c|c|}
\hline & $A C+E L V$ & PseudoFalcon-I & PseudoFalcon-V & \\
\hline Define Gross Profit Ratio & 2.00 & 2.00 & 2.00 & ratio \\
\hline Circular LEO Velocity & 7,905 & 7,905 & 7,905 & $\mathrm{~m} / \mathrm{sec}$ \\
\hline Drag \& Loss Fraction & $4 \%$ & $15 \%$ & $15 \%$ & pct \\
\hline Actual Delta-V to LEO & 8,221 & 9,091 & 9,091 & $\mathrm{~m} / \mathrm{sec}$ \\
\hline Stages & 2 & 2 & 2 & \\
\hline Exhaust Velocity & 2,798 & 2,798 & 2,798 & $\mathrm{~m} / \mathrm{sec}$ \\
\hline Fuel Density & 0.810 & 0.810 & 0.810 & $\mathrm{~g} / \mathrm{cm}^{3}$ \\
\hline Oxidizer:Fuel Wt Ratio & 2.24 & 2.24 & 2.24 & ratio \\
\hline LOX Density & 1.140 & 1.140 & 1.140 & $\mathrm{~g} / \mathrm{cm}^{3}$ \\
\hline Mass Ratio, Stage & 4.345 & 5.076 & 5.076 & ratio \\
\hline Propellant & 0.7699 & 0.8030 & 0.8030 & fraction \\
\hline Payload:Total Dry & 0.097 & 0.125 & 0.169 & fraction \\
\hline Recovery:Total Dry & 0.000 & 0.000 & 0.000 & fraction \\
\hline Payload Mass & 1,168 & 1,474 & 13,244 & $\mathrm{lb}$ \\
\hline Other Structural Mass & 10,863 & 10,346 & 65,309 & $\mathrm{lb}$ \\
\hline Recovery System Mass & 0 & 0 & 0 & $\mathrm{lb}$ \\
\hline Total Dry Mass & 12,031 & 11,820 & 78,553 & $\mathrm{lb}$ \\
\hline Propellant Mass & 40,249 & 48,179 & 320,175 & $\mathrm{lb}$ \\
\hline Gross Take Off Mass & 52,280 & 59,999 & 398,728 & $\mathrm{lb}$ \\
\hline Fuel Cost & 0.308 & 0.308 & 0.308 & $\$ / l b$ \\
\hline LOX Cost & 0.298 & 0.298 & 0.298 & $\$ / l b$ \\
\hline Propellant Cost & 0.301 & 0.301 & 0.301 & $\$ / l b$ \\
\hline Vehicle Flight Lifetime & 1 & 1 & 1 & count \\
\hline Fleet Size & 500 & 500 & 500 & count \\
\hline Program Lifetime & 10 & 10 & 10 & years \\
\hline Interest Cost & $12.00 \%$ & $12.00 \%$ & $12.00 \%$ & $\% /$ year \\
\hline Catastrophic Failure Rate & $1.00 \%$ & $0.20 \%$ & $0.20 \%$ & $\%$ \\
\hline Maximum Probable Loss & $21,783,600$ & $24,999,906$ & $166,137,988$ & $\$$ \\
\hline Structure Cost & 74.09 & 72.73 & 59.85 & $\$ / \mathrm{lb}$ \\
\hline Structure Cost & 804,844 & 752,443 & $3,908,910$ & $\$ /$ vehicle \\
\hline Flight Refurbish Cost & $0.0 \%$ & $0.0 \%$ & $0.0 \%$ & $\%$ Structure \\
\hline Prelaunch Prep Time & 113 & 134 & 324 & $\mathrm{hr}$ \\
\hline Prelaunch Prep Rate & 50.00 & 50.00 & 50.00 & $\$ / \mathrm{hr}$ \\
\hline Structure Cost & 804,844 & 752,443 & $3,908,910$ & \$/flight \\
\hline Propellant Cost & 12,118 & 14,506 & 96,400 & \$/flight \\
\hline Flight Refurbish Cost & 0 & 0 & 0 & \$/flight \\
\hline Prelaunch Prep Cost & 5,674 & 6,685 & 16,220 & \$/flight \\
\hline Direct Launch Cost & 822,637 & 773,634 & $4,021,531$ & \$/flight \\
\hline Direct Launch Cost & 704.31 & 524.85 & 303.65 & $\$ /$ lb LEO \\
\hline Program R \& D & $61,802,497$ & $79,487,060$ & $246,353,355$ & $\$$ \\
\hline
\end{tabular}

American Institute of Aeronautics and Astronautics 
Table 9. LEO Cost Spreadsheet Using Risk Based Insurance. Table 9 is a reformulation of Table 7 using risk based insurance in place of the standard insurance.

\begin{tabular}{|c|c|c|c|c|c|c|c|}
\hline & ELV & RLV & MedELV & MedRLV & Big ELV & Big RLV & \\
\hline Define Gross Profit Ratio & 2.00 & 2.00 & 2.00 & 2.00 & 2.00 & 2.00 & ratio \\
\hline Circular LEO Velocity & 7,905 & 7,905 & 7,905 & 7,905 & 7,905 & 7,905 & $\mathrm{~m} / \mathrm{sec}$ \\
\hline Drag \& Loss Fraction & $15 \%$ & $15 \%$ & $15 \%$ & $15 \%$ & $15 \%$ & $15 \%$ & pct \\
\hline Actual Delta- $V$ to LEO & 9,091 & 9,091 & 9,091 & 9,091 & 9,091 & 9,091 & $\mathrm{~m} / \mathrm{sec}$ \\
\hline Stages & 2 & 2 & 2 & 2 & 2 & 2 & \\
\hline Exhaust Velocity & 2,798 & 2,798 & 2,798 & 2,798 & 2,798 & 2,798 & $\mathrm{~m} / \mathrm{sec}$ \\
\hline Fuel Density & 0.810 & 0.810 & 0.810 & 0.810 & 0.810 & 0.810 & $\mathrm{~g} / \mathrm{cm}^{3}$ \\
\hline Oxidizer:Fuel Wt Ratio & 2.24 & 2.24 & 2.24 & 2.24 & 2.24 & 2.24 & ratio \\
\hline LOX Density & 1.140 & 1.140 & 1.140 & 1.140 & 1.140 & 1.140 & $\mathrm{~g} / \mathrm{cm}^{3}$ \\
\hline Mass Ratio, Stage & 5.076 & 5.076 & 5.076 & 5.076 & 5.076 & 5.076 & ratio \\
\hline Propellant & 0.8030 & 0.8030 & 0.8030 & 0.8030 & 0.8030 & 0.8030 & fraction \\
\hline Payload:Total Dry & 0.125 & 0.090 & 0.263 & 0.195 & 0.400 & 0.300 & fraction \\
\hline Recovery:Total Dry & 0.000 & 0.250 & 0.000 & 0.250 & 0.000 & 0.250 & fraction \\
\hline Payload Mass & 1,000 & 1,000 & 10,000 & 10,000 & 100,000 & 100,000 & lb \\
\hline Other Structural Mass & 7,000 & 7,333 & 28,095 & 28,462 & 150,000 & 150,000 & Ib \\
\hline Recovery System Mass & 0 & 2,778 & 0 & 12,821 & 0 & 83,333 & $\mathrm{lb}$ \\
\hline Total Dry Mass & 8,000 & 11,111 & 38,095 & 51,282 & 250,000 & 333,333 & lb \\
\hline Propellant Mass & 32,607 & 45,288 & 155,273 & 209,022 & $1,018,981$ & $1,358,641$ & $\mathrm{lb}$ \\
\hline Gross Take Off Mass & 40,607 & 56,399 & 193,369 & 260,304 & $1,268,981$ & $1,691,975$ & $\mathrm{lb}$ \\
\hline Fuel Cost & 0.308 & 0.308 & 0.308 & 0.308 & 0.308 & 0.308 & $\$ / \mathrm{lb}$ \\
\hline LOX Cost & 0.298 & 0.298 & 0.298 & 0.298 & 0.298 & 0.298 & $\$ / \mathrm{lb}$ \\
\hline Propellant Cost & 0.301 & 0.301 & 0.301 & 0.301 & 0.301 & 0.301 & $\$ / \mathrm{lb}$ \\
\hline Vehicle Flight Lifetime & 1 & 100 & 1 & 100 & 1 & 100 & count \\
\hline Fleet Size & 500 & 5 & 500 & 5 & 500 & 5 & count \\
\hline Program Lifetime & 10 & 10 & 10 & 10 & 10 & 10 & years \\
\hline Interest Cost & $12.00 \%$ & $12.00 \%$ & $12.00 \%$ & $12.00 \%$ & $12.00 \%$ & $12.00 \%$ & $\% /$ year \\
\hline Catastrophic Failure Rate & $1.00 \%$ & $0.20 \%$ & $1.00 \%$ & $0.20 \%$ & $1.00 \%$ & $0.20 \%$ & $\%$ \\
\hline Maximum Probable Loss & $16,919,882$ & $23,499,836$ & $80,570,867$ & $108,460,782$ & $528,746,313$ & $704,995,085$ & $\$$ \\
\hline Structure Cost & 75.00 & 400.00 & 61.50 & 325.00 & 48.00 & 250.00 & $\$ / \mathrm{lb}$ \\
\hline Structure Cost & 525,000 & $4,044,444$ & $1,727,857$ & $13,416,667$ & $7,200,000$ & $58,333,333$ & $\$ /$ vehicle \\
\hline Flight Refurbish Cost & $0.0 \%$ & $2.0 \%$ & $0.0 \%$ & $2.0 \%$ & $0.0 \%$ & $2.0 \%$ & $\%$ Structure \\
\hline Prelaunch Prep Time & 100 & 125 & 300 & 375 & 500 & 625 & $\mathrm{hr}$ \\
\hline Prelaunch Prep Rate & 50.00 & 50.00 & 50.00 & 50.00 & 50.00 & 50.00 & $\$ / h r$ \\
\hline Structure Cost & 525,000 & 40,444 & $1,727,857$ & 134,167 & $7,200,000$ & 583,333 & \$/flight \\
\hline Propellant Cost & 9,818 & 13,636 & 46,751 & 62,934 & 306,801 & 409,068 & \$/flight \\
\hline Flight Refurbish Cost & 0 & 80,080 & 0 & 265,650 & 0 & $1,155,000$ & \$/flight \\
\hline Prelaunch Prep Cost & 5,000 & 6,250 & 15,000 & 18,750 & 25,000 & 31,250 & \$/flight \\
\hline Direct Launch Cost & 539,818 & 140,410 & $1,789,608$ & 481,500 & $7,531,801$ & $2,178,652$ & \$/flight \\
\hline Direct Launch Cost & 539.82 & 140.41 & 178.96 & 48.15 & 75.32 & 21.79 & $\$ /$ lb LEO \\
\hline Program R \& D & $50,000,000$ & $75,000,000$ & $225,000,000$ & $337,500,000$ & $400,000,000$ & $600,000,000$ & $\$$ \\
\hline Launch Facility Costs & $2,000,000$ & $2,000,000$ & $6,000,000$ & $6,000,000$ & $10,000,000$ & $10,000,000$ & $\$$ \\
\hline Program Lifetime & 500 & 500 & 500 & 500 & 500 & 500 & flights \\
\hline Flight Rate & 50 & 50 & 50 & 50 & 50 & 50 & flights/year \\
\hline Program R \& D & 100,000 & 150,000 & 450,000 & 675,000 & 800,000 & $1,200,000$ & \$/light \\
\hline Range Costs & 476,530 & 580,426 & 970,115 & $1,064,126$ & $1,565,134$ & $1,656,119$ & $\$ /$ flight \\
\hline Launch Facility Costs & 4,000 & 4,000 & 12,000 & 12,000 & 20,000 & 20,000 & $\$ /$ flight \\
\hline Recovery Costs & 0 & 50,000 & 0 & 125,000 & 0 & 200,000 & \$/flight \\
\hline Adjust Recovery Costs & 0 & 49,500 & 0 & 123,750 & 0 & 198,000 & \$/flight \\
\hline "Standard" Insurance & 379,500 & 919,616 & $1,161,429$ & $2,955,160$ & $2,583,750$ & $10,427,938$ & $\$ /$ flight \\
\hline Alt:Risk-Based Insure & 405,267 & 187,623 & $1,929,841$ & 865,954 & $12,664,582$ & $5,628,703$ & \$/flight \\
\hline Indirect Launch Costs & 856,030 & $1,549,542$ & $2,131,543$ & $4,143,036$ & $4,148,884$ & $12,282,056$ & \$/flight \\
\hline Alt:Risk-Based Indirect & 881,797 & 817,549 & $2,899,956$ & $2,053,830$ & $14,229,716$ & $7,482,822$ & \$/flight \\
\hline Indirect Launch Costs & 856.03 & $1,549.54$ & 213.15 & 414.30 & 41.49 & 122.82 & \$/b LEO \\
\hline Alt:Risk-Based Indirect & 881.80 & 817.55 & 290.00 & 205.38 & 142.30 & 74.83 & $\$ / \mathrm{lb}$ LEO \\
\hline Indirect+R\&D+Facility & 960,030 & $1,703,542$ & $2,593,543$ & $4,830,036$ & $4,968,884$ & $13,502,056$ & \$/light \\
\hline Indirect+R\&D+Facility & 960.03 & $1,703.54$ & 259.35 & 483.00 & 49.69 & 135.02 & $\$ / \mathrm{lb}$ LEO \\
\hline R\&D \& Facility Amort & $8,849,916$ & $13,274,520$ & $39,823,561$ & $59,734,279$ & $70,797,205$ & $106,194,038$ & \$/year \\
\hline R\&D \& Facility Amort & 176,998 & 265,490 & 796,471 & $1,194,686$ & $1,415,944$ & $2,123,881$ & $\$ /$ flight \\
\hline$R \& D$ \& Facility Amort & 177.00 & 265.49 & 79.65 & 119.47 & 14.16 & 21.24 & $\$ /$ lb LEO \\
\hline Total Launch Cost & $1,572.85$ & $1,955.44$ & 471.76 & 581.92 & 130.97 & 165.85 & $\$ / \mathrm{lb}$ LEO \\
\hline Alt:Risk-Based Total & $1,598.61$ & $1,223.45$ & 548.60 & 373.00 & 231.77 & 117.85 & $\$ / \mathrm{lb}$ LEO \\
\hline Total Program Delivery & 500,000 & 500,000 & $5,000,000$ & $5,000,000$ & $50,000,000$ & $50,000,000$ & lb LEO \\
\hline Total Program Cost & 0.786 & 0.978 & 2.359 & 2.910 & 6.548 & 8.292 & \$ Billion \\
\hline Units Delivered & 500 & 500 & 500 & 500 & 500 & 500 & count LEO \\
\hline \multirow[t]{2}{*}{ Program Lifetime } & 10 & 10 & 10 & 10 & 10 & 10 & years \\
\hline & ELV & RLV & MedELV & MedRLV & Big ELV & Big RLV & \\
\hline
\end{tabular}




\section{Acknowledgments}

Any errors or omissions in this paper are the responsibility of the authors. However, we thank the following for their helpful discussions, comments, and criticisms:

Dr. Loren Acton; Mr. David Ashford; Mr. Pat Bahn; Mr. Jim Benson; Dr. Patrick Collins; Mr. Paul Contursi; Dr. Brad Edwards; Mr. John Garvey; Mr. Kevin Greene; Col. Gary Henry, USAF; Nathan Horsley, Esq.; Ms. Joan Horvath; Dr. Dave Klumpar; Mr. Joe Latrell; Mr. Clark Lindsey; Mr. Tom Olson; Dr. Jerry Pournelle; David Rankin, Esq.; Dr. Eligar Sedeh; Mr. Rand Simberg; Dr. Harvey Willenberg; and Mr. Al Zaehringer.

If we have inadvertently omitted somebody from this list who provided us with valuable feedback, we apologize.

\section{The Authors}

\section{Dr. John Jurist}

John is a biophysicist with a long-standing interest in human factors in space flight. In addition to occasional consulting, John is an investor in XCOR Aerospace, has supported other alt.space start-up activities with grants, and is currently funding certain rocket propulsion projects in the Space Science and Engineering Laboratory at Montana State University and certain avionics projects in the Robotics Laboratory at Santa Clara University. He also writes a periodic column on human factors in space flight (www.thespacereview.com).

He earned his undergraduate degree in physics at UCLA and graduate degrees in biophysics and nuclear medicine while at the UCLA School of Medicine. After postdoctoral training in the Department of Radiology at the University of Wisconsin, he held faculty positions in the Division of Orthopedic Surgery and in the Space Science and Engineering Center at that same institution. As a researcher, he led the team that first transmitted medical X-ray images over satellite links in a forerunner of modern telemedicine, studied the effects of weightlessness on bone metabolism, and studied methods of noninvasively evaluating bone strength in humans.

Among other professional associations, John is currently a Life Member of the Aerospace Medical Association (Space Medicine Branch) and a Fellow of the Clinical Medicine Section of the Gerontological Society. John was appointed by the Governor of Montana to the Board of Health and Environmental Sciences, founded and ran a research institute at a large medical center, was CEO of an ambulatory surgical center, and has held adjunct or part time professorships in physics, engineering, and medical sciences in the Montana State University System.

The opinions expressed in this paper do not necessarily reflect the opinions or policies of XCOR Aerospace, Montana State University, or Santa Clara University.

John currently resides in Billings, Montana and can be contacted at JMJSpace@aol.com .

2. Dr. Sam Dinkin

Sam is a regular columnist at The Space Review and the founder of SpaceShot, Inc. (www.space-shot.com) He is a space investor in early stage companies. Sam is also the sponsor of the Space Journalism Prize (www.spacejournalism.com) and is currently forming the Space Journalism Association.

Sam is also Chief Economist of Optimal Auctions, Inc. (www.optimalauctions.com). He designed and implemented auctions for over $\$ 90$ billion in cost of goods sold including all of the electricity for New Jersey rate payers since 2002. Prior to that, he was an applied visionary at IBM Research. While there, he filed over 100 patents including a recently granted broad patent covering all externally adjustable medical implants.

Sam's Ph.D. in economics from the University of Arizona was under thesis advisor Vernon Smith, 2002 Nobel Laureate in economics. His B.S. in economics is from Caltech.

Sam can be contacted at (888) 434-6546 or sam@ dinkin.com.

\section{Dr. David Livingston}

David is the founder and host of the nation's only talk radio show focusing on increasing space commerce, developing space tourism, and facilitating our move to a space-faring culture. "The Space Show®" is broadcast twice weekly on radio, the internet, and on satellite. Past show archives and listening information can be found at www.thespaceshow.com.

David is currently an adjunct professor at the University of North Dakota Graduate School of Space Studies teaching "Ethics and Space Commerce." He also served as an adjunct professor in the Graduate School of Business at Golden Gate University where he taught "Entrepreneurship and Small Business Management." He earned his B.A. from the University of Arizona, an M.B.A. in International Business Management from Golden Gate University in San Francisco, and his doctorate in business administration (D.B.A.) at Golden Gate University. His doctoral dissertation was titled Outer Space Commerce: Its History and Prospects. 
David has spoken at or had his papers presented at various international space conferences including Space and Robotics, the Mars Society conferences, the Lunar Development Conferences, IAA, the Cato Institute, the World Space Conference, and the National Space Society Conference. His lecture topics include business ethics, corporate responsibility for off-Earth business ventures and New Space Industries, venture capital financing for new space businesses, RLVs and space tourism, effective business, strategic, and assumption planning, and developing the solutions to the barriers to space enterprise. David has appeared as a guest on the Coast to Coast radio program discussing space commerce and tourism, Red FM in Cork, Ireland discussing space tourism and doing space news updates, and as a guest on other national talk shows, both on the radio and the internet. He is also an active member of several space advocacy organizations.

When not occupied or working with space matters, David is a business consultant, financial advisor, and strategic planner. For more than 25 years, he has worked in oil and gas exploration, real estate development and sales, finance, marketing, and direct advertising and sales. He currently specializes in solving business problems for entrepreneurial operations, startups, and businesses with 10 or fewer employees in addition to his writing, lecturing, and consulting on commercial space matters.

David can be contacted at (415) 435-6018 or dlivings@ davidlivingston.com.

\title{
References
}

\author{
1966. \\ ${ }^{1}$ Taylor, T., "Propulsion of Space Vehicles", in Marshak, R., Perspectives in Modern Physics. Wiley-Interscience, New York, \\ ${ }^{2}$ Baker, R., Jr. and Makemson, M., An Introduction to Astrodynamics. Academic Press, New York, 1960. \\ ${ }^{3}$ Zaehringer and Whitfield, S., Rocket Science. Apogee Books, Burlington, Ontario, Canada, 2004. \\ ${ }^{4}$ Berman, The Physical Principles of Astronautics. John Wiley \& Sons, Inc., New York, 1961. \\ ${ }^{5}$ Sutton, G., Rocket Propulsion Elements, 6th Edition. John Wiley \& Sons, Inc., New York, 1992. \\ ${ }^{6}$ Space Exploration Technologies Corporation (SpaceX): Corporate Website. http://web.archive.org/web/20040605224038/ \\ http://www.spacex.com/, El Segudo, CA, June 9, 2005.
}

${ }^{7}$ URS Corporation, "Site-Wide Environmental Assessment, Wallops Flight Facility, Virginia," Gathersburg, MD, January 2005 , p. 36.

${ }^{8}$ Orbital Sciences Corporation, Pegasus User's Guide Release 5.0, http://www.orbital.com/NewsInfo/Publications/peg-userguide.pdf, Dulles, VA, August, 2000.

${ }^{9}$ Henry, G., "The Decision Maker's Guide to Robust, Reliable and Inexpensive Access to Space," Occasional Paper No. 37, Air War College, Maxwell AFB, AL, July, 2004.

${ }^{10}$ Aerospaceweb.org, http://web.archive.org/web/20041022193826/http://www.aerospaceweb.org/aircraft/transport-m/an225/

${ }^{11}$ Sarigul-Klijn, M., and Sarigul-Klijn, N., "A Study of Air Launch Methods for RLVs," AIAA Paper 2001-4619, AIAA, Reston, VA, 2001.

${ }^{12}$ US Department of Energy, http://web.archive.org/web/20041012140229/http://www.eere.energy.gov/hydrogenandfuelcells/ faqs hydrogen.html, Washington, DC, July 21, 2004.

${ }^{13}$ Airbus, Corporate Website, http://web.archive.org/web/20040305113700/www.airbus.com/product/a380_specifications .asp, Toulouse, France, February 4, 2005.

${ }^{14}$ Kuennen, T., Knorreck, H., Elson, M., and Buckley, S., "Reducing the cost of launching small satellites: A perspective from the field," Paper SSC04-X-1, Proc. 18th Annual AIAA/USU Conference on Small Satellites, Logan, UT 2004.

${ }^{15}$ Dobbs, L., and Newquist, H., Space: The Next Business Frontier, Pocket Books, New York, 2001.

${ }^{16}$ Futron Corporation, "Design Reliability Comparison for SpaceX Falcon Vehicles," Bethesda, MD, November, 2004. (Available at http://www.spacex.com/FutronDesignReliability.pdf in January 2005 update).

${ }^{17}$ Doman, T. D., and Markus, M., "Brokers vs. Insurers," McKinsey Quarterly, No. 3, McKinsey and Company, Inc., New York, 1999.

${ }^{18}$ McDowell, J., "Jonathan's Space Home Page," http://web.archive.org/web/20031022184419/http://www.planet4589.org/ space/lvdb/index.html, March 20, 2005.

${ }^{19}$ Eilingsfeld, F., and Schaetzler, D., "The Cost of Capital for Space Tourism Ventures," Proceedings of 2nd ISST, DaimlerChrysler GmbH., http://www.spacefuture.com/archive/the_cost_of_capital_for_space_ventures.shtml, Berlin, Germany, 1999.

${ }^{20}$ Ashford, D., Spaceflight Revolution, Imperial College Press, London, 2002.

${ }^{21}$ Muncy, J., Interview on The Space Show, http://archived.thespaceshow.com/shows/338-BWB-2005-05-16.mp3, Tiburon, CA, May 16, 2005.

${ }^{22}$ Bloomberg, http://spinwatch.server101.com/modules.php?name=News\&file=article\&sid=341, December 31, 2004.

${ }^{23}$ Truth and Politics, http://web.archive.org/web/20040606013250/http://www.truthandpolitics.org/2004-outlays-summary .php, 2004. 
${ }^{24}$ Internal Revenue Service, http://web.archive.org/web/20040413153616/http://www.irs.gov/businesses/page/0,,id=6999,00 . html\#Rate5, Washington, DC, April, 2004.

${ }^{25}$ Koshkina, Elvira, "New Launch Vehicle 'Ladoga-1P' Will Place Satellites in the Near Earth Orbits" http://science.compulenta.ru/188775/, Russia, June 24, 2005.

${ }^{26}$ O'Keefe, S., as quoted in, Rogers, A., "The Man Who Runs NASA," Wired, http://www.wired.com/wired/archive/12.12/ okeefe.html, The Condé Nast Publications, San Francisco, CA, December 2004.

${ }^{27}$ Griffin, M., as quoted in Cowing, K., "Mike Griffin Reveals His Commercialization Vision for NASA: Part 1", Spaceref, http://www.spaceref.com/news/viewnews.html?id=1034, Reston, VA, June 21, 2005.

${ }^{28}$ Cringley, R., "What Carly Will Be Missing: High-Tech is Going Through Another Revolution, and Ms. Fiorina Couldn't Keep Up.” http://www.pbs.org/cringely/pulpit/pulpit20050210.html, PBS, Washington, DC, February 10, 2005.

${ }^{29}$ Isozaki, K., et al, "Status Report on Space Tour Vehicle 'Kankow-maru' of Japanese Rocket Society," IAF paper no IAA98-IAA.1.5.06, http://www.spacefuture.com/ archive/status report on space tour vehicle kankoh maru of japanese rocket society.shtml, 1998.

${ }^{30}$ Collins, P., and Isozaki, K., “The Japanese Rocket Society's Space Tourism Research,” International Symposium on Space Tourism, Bremen, Germany, March 20-22, 1997. Text available at http://www.spacefuture.com/archive.

${ }^{31}$ Crichton, M., "Aliens Cause Global Warming," Lecture at the California Institute of Technology, Pasadena, CA, January 17, 2003. Text available at http://www.crichton-official.com/speeches/index.html. 